\title{
SYNTHESIS AND CHARACTERIZATION OF A NEW MONOMETALLIC MANGANESE LAYERED DOUBLE HYDROXIDE WITH UNIQUE REDOX PROPERTIES
}

A PREPRINT

\author{
Damien Cornu* \\ LCPME UMR 7564 \\ Université de Lorraine - CNRS, \\ F-54000 Villers-lès-Nancy, France \\ damien. cornu@univ-lorraine.fr
}

\author{
Romain Coustel \\ LCPME UMR 7564 \\ Université de Lorraine, CNRS, \\ F-54000 Villers-lès-Nancy, France
}

\author{
Aurélien Renard \\ LCPME UMR 7564 \\ Université de Lorraine, CNRS, \\ F-54000 Villers-lès-Nancy, France
}

\author{
Pierrick Durand \\ CRM2 UMR 7036 \\ Université de Lorraine, CNRS, \\ F-54000 Vandoeuvre-lès-Nancy, France
}

\author{
Cédric Carteret \\ LCPME UMR 7564 \\ Université de Lorraine, CNRS, \\ F-54000 Villers-lès-Nancy, France
}

\author{
Christian Ruby* \\ LCPME UMR 7564 \\ Université de Lorraine, CNRS, \\ F-54000 Villers-lès-Nancy, France \\ christian.ruby@univ-lorraine.fr
}

September 30, 2020

\begin{abstract}
Iron and cobalt monometallic Layered Double Hydroxide (LDH), combining divalent and trivalent cations of the same chemical element, are commonly used respectively for nitrate reduction and oxygen evolution reaction. This article reports the first synthesis of a LDH using only manganese as metallic ion. X-Ray diffractograms, infrared and Raman spectra show that the structure obtained through the oxidation of a basic $\mathrm{Mn}^{\mathrm{II}}$ salt with persulfate is comparable to the structure of Fe-LDH also known as Green Rust. XPS shows that in this solid coexist $\mathrm{Mn}^{\mathrm{II}}$ and $\mathrm{Mn}^{\mathrm{III}}$ states. Thermodynamic considerations predict that this solid can reduce nitrate into gaseous nitrogen without further reduction into ammonium or ammonia unlike what is observed for Fe-LDH.
\end{abstract}

Keywords $\mathrm{Mn}_{6}(\mathrm{OH})_{12} \mathrm{SO}_{4} \cdot \mathrm{LDH} \cdot \mathrm{Mn} \cdot$ Green rust $\cdot$ Mn basic salts $\cdot$ XPS $\cdot$ XRD $\cdot$ Raman $\cdot$ IR $\cdot$ SEM $\cdot$ Monometallic LDH $\cdot$ Water remediation $\cdot$ Nitrate reduction $\cdot$ Pourbaix diagram $\cdot$ Thermodynamic calculation

\section{Introduction}

Layered double hydroxides (LDH), or anionic clays are a class of ionic solid with a layered structure and a general formula $\left[\mathrm{M}_{1-\mathrm{x}}^{\mathrm{II}} \mathrm{M}_{\mathrm{x}}^{\mathrm{III}}(\mathrm{OH})_{2}\right]^{\mathrm{x}+}\left[\mathrm{A}_{\mathrm{x} / \mathrm{n}}^{\mathrm{n}-}\right]^{\mathrm{x}-} \cdot \mathrm{mH}_{2} \mathrm{O}$ in which $\mathrm{M}^{\mathrm{II}}$ and $\mathrm{M}^{\mathrm{III}}$ are metallic cations and $\mathrm{A}^{\mathrm{n}-}$ an intercalated anion. These materials are useful structures for many applications, e.g., catalysis (oxygen evolution reaction [1], photodegradation of pollutants [2]), for anionic exchange [3] or biomedical applications [4]. They are usually synthesized using a trivalent cation distinct from the divalent cations (e.g. $\mathrm{Al}^{3+}$ as $\mathrm{M}^{\mathrm{III}}$ and $\mathrm{Mg}^{2+}$ as $\mathrm{M}^{\mathrm{II}}$ for the common hydrotalcite AlMg-LDH) [5]. But it is possible to synthesize such structure using only one metallic element. This is well known for iron, the Fe-LDH also known as "Green rust" [6, 7] or "Fougerite" [8, 9]. Sulfate Fe-LDH is very 
active for reducing nitrate into ammonium species [10]. This mono-metallic layered structure is also observed for cobalt [11, 12], forming single transition metal hydroxide with mixed valences. This monometallic Co-LDH can be used as capacitors with high pseudocapacitive performance [13] or for oxygen evolution reaction. In addition, cerium monometallic LDH exist with interesting photocatalitic properties [14] but the high oxidation state of $\mathrm{Ce}\left(\mathrm{Ce}^{3+}-\mathrm{Ce}^{4+}\right)$ impose the substitution of $\mathrm{OH}^{-}$by $\mathrm{SO}_{4}^{2-}$. Lanthanide-LDH have also been synthetized [15]. Ni monometallic LDH are also mentioned in the literature, but without convincing proof of their synthesis [16].

Manganese is frequently incorporated in LDH structures: as a divalent cation with $\mathrm{Al}^{3+}[17,18,19]$ or as a trivalent cation with $\mathrm{Mg}^{2+}, \mathrm{Zn}^{2+}$ or $\mathrm{Co}^{2+}[20,21,22,23]$ because of its photocatalytic potential [24]. These $\mathrm{LDH}$ can be used for phototherapy against cancers [25], for electrocatalytic detection of hydrogen peroxide [23] or as an electrode for oxygen [26]. However, to our knowledge, it was never used as single metallic constituent of a LDH. One of the main limitation is the impossibility to get a stable $\mathrm{Mn}^{\mathrm{III}}$ solution excluding the classical coprecipitation method using an initial solution prepared by the dissolution of $\mathrm{Mn}^{\mathrm{II}}$ and $\mathrm{Mn}^{\mathrm{III}}$ salts. The $\mathrm{Mn}^{\mathrm{III}}$ cations contained in the $\mathrm{LDH}$ are obtained by either introducing an oxidant such as $\mathrm{H}_{2} \mathrm{O}_{2}$ in the initial solution [27] or was probably due to the contact of the LDH suspension with air [28, 29].

An another synthesis pathway is the oxidation of $\mathrm{M}^{\mathrm{II}}$ hydroxide. $\mathrm{Mn}(\mathrm{OH})_{2}$ oxidation was thoroughly studied an half century ago [30] and it appeared that the formation of oxide $\left(\mathrm{Mn}_{3} \mathrm{O}_{4}\right.$ or birnessite [31]) or oxide-hydroxide $(\mathrm{MnOOH})$ was the sole fate. However, using a basic $\mathrm{Mn}$ (II) salt as a precursor, we are able to synthesize a Mn-LDH with sulfate anions in the interlayer space. In addition to the potential use for catalysis, the possibility to stabilise a mixed $\mathrm{Mn}^{\mathrm{II}}-\mathrm{Mn}^{\mathrm{III}}$ species in a hydroxide structure opens new perspectives because of their redox properties. Indeed, soluble $\mathrm{Mn}_{(\mathrm{aq})}^{2+}$ species are well known to be very slowly oxidised by soluble oxygen in acidic or neutral aqueous solutions. $\mathrm{Mn}^{\mathrm{II}}$ species present in more compact solid structure such as spinels (e.g. hausmannite) are well known to be stable in contact with air. On the contrary hyroxylated $\mathrm{Mn}^{\mathrm{II}}$ species present in an opened solids structure such as $\mathrm{LDH}$ are expected to be much more reactive. Such differences of reactivity were clearly demonstrated in the case of $\mathrm{Fe}^{\mathrm{II}}$ containing compound, i.e., the oxidation of $\mathrm{Fe}(\mathrm{OH})_{2}$ or $\mathrm{Fe}_{3} \mathrm{O}_{4}$ by $\mathrm{NO}_{3}^{-}$is extremely slow in comparison to the nitrate oxidation of Fe-LDH [32]. Finally, the existence of a mixed $\mathrm{Mn}^{\mathrm{II}}-\mathrm{Mn}^{\mathrm{III}} \mathrm{LDH}$ structure has to be considered when analysing the oxidation of $\mathrm{Mn}^{\mathrm{II}}$ in geology. Indeed, the source of $\mathrm{Mn}^{\mathrm{III}}$ in aqueous media is still debated [33].

\section{Experimental section}

\subsection{Synthesis}

Mn-LDH were synthesized using $50 \mathrm{~mL}$ of a $\mathrm{MnSO}_{4} \cdot \mathrm{H}_{2} \mathrm{O}$ (Sigma Aldrich, $>99 \%$ ) solution $\left(0.4\right.$ mol. $\mathrm{L}^{-1}$ ) with a variable volume of a 1 mol. $\mathrm{L}^{-1} \mathrm{NaOH}$ (VWR 31627.290) to reach the desired $\mathrm{R}$ value $\left(\mathrm{R}=\frac{\mathrm{n}\left(\mathrm{OH}^{-}\right)}{\mathrm{n}\left(\mathrm{Mn}^{2+}\right)}\right)$ under stiring and nitrogen bubling. Once the $\mathrm{pH}$ was stabilized, a 0.2 or $0.5 \mathrm{~mol} . \mathrm{L}^{-1}$ solution of $\mathrm{Na}_{2} \mathrm{~S}_{2} \mathrm{O}_{8}$ (Sigma Aldrich, >99\%) was added by a perilstatic pump with a $0.167 \mathrm{~mL} \cdot \mathrm{min}^{-1}$ flow and the $\mathrm{pH}$ as well as the redox potential $\mathrm{E}_{\mathrm{h}}$ were registered with a Metrohm pH electrode Unitrode with Pt1000 and a Toledo Inlab redox electrode. The $\mathrm{x}$ value indicates the quantity of persulfate introduced, as $\mathrm{x}=2 \frac{\mathrm{n}\left(\mathrm{S}_{2} \mathrm{O}_{8}^{2-}\right)}{\mathrm{n}\left(\mathrm{Mn}^{2+}\right)}$.

For XPS analysis, $\mathrm{Mn}(\mathrm{OH})_{2}$ was prepared from a mixture of $1.12 \mathrm{~g}$ of $\mathrm{MnCl}_{2} \cdot 4 \mathrm{H}_{2} \mathrm{O}$ (Sigma Aldrich, $>98 \%$ ) and 0.57 $\mathrm{g}$ of $\mathrm{NaOH}(\mathrm{VWR}, 99,1 \%)$ in $40 \mathrm{ml}$ of water under nitrogen bubbling.

\subsection{Characterization}

\subsubsection{XRD}

The products were measured soon after the synthesis and the centrifugation. XRD diffractograms were recorded either on wet sample ( $\mathrm{x}=0,0.12$ and 0.24$)$ or on sample dried under nitrogen flow $(\mathrm{x}=1)$. For the wet sample, excess of water was removed by pressing the water soaked paste between tissues. The resulting paste was measured on an approximately $10 \mu \mathrm{m}$ thick zero background X-ray holder covered with a minimal amount of glycerol to protect the paste from air oxidation, as the compounds were known to be air sensitive. Multiple (at least 15) $1 \mathrm{~h} \mathrm{X-ray} \mathrm{scans} \mathrm{were}$ collected, and the diffractograms did not show any sign of evolution, the multiple scans were summed up for better X-ray statistics.

Powder X-ray diffraction patterns were recorded with a Panalytical X'Pert Pro MPD diffractometer in reflection geometry using a tube with $\mathrm{Cu}$ radiation $\left(\mathrm{K} \alpha_{1}=1.5406 \AA\right)$, a $\mathrm{Ge}(111)$ incident-beam monochromator, $0.02 \mathrm{rad}$ 
Soller slits, programmable divergence and antiscatter slits (the irradiated area was fixed to $10 \mathrm{~mm} \times 10 \mathrm{~mm}$ ), and an $\mathrm{X}$ 'Celerator detector. Data were collected from finely ground samples with a sample holder spinner and continuous rotation of sample to improve statistical representation of the sample.

\subsubsection{XPS}

X-ray photoelectron spectra were recorded on a KRATOS Axis Ultra Xray photoelectron KRATOS Axis Ultra DLD spectrometer equipped with a monochromated $\mathrm{Al} \mathrm{K} \alpha$ source ( $\mathrm{h} \nu=1486.6 \mathrm{eV}$, spot size $0.7 \mathrm{~mm} \times 0.3 \mathrm{~mm})$. The detector was a hemispherical analyzer at an electron emission angle of $90^{\circ}$ and pass energy of $20 \mathrm{eV}$ (high resolution spectra). For the high-resolution spectra, the overall energy resolution, resulting from monochromator and electron analyzer bandwidths, was better than $800 \mathrm{meV}$. The $\mathrm{C} 1 \mathrm{~s}$ binding energy of adventitious carbon was taken as $284.6 \mathrm{eV}$. O1s spectra were decomposed using Gaussian peaks after using Shirley method of background subtraction.

\subsubsection{Vibrational spectroscopies}

- Infrared IR measurements of the wet solids were recorded under nitrogen flow in a Attenuated Total Reflectance mode on a Bruker Tensor 27 spectrometer equipped with a $\mathrm{KBr}$ beam splitter and a deuterated triglycine sulfate (DTGS) thermal detector. Spectra were recorded and processed using OPUS 7.5 software (Bruker, Karlsruhe, Germany).

- Raman $10 \mu \mathrm{L}$ sample were collected and dried over a aluminium plate. Then Raman spectra were collected on a Renishaw inVia ${ }^{\mathrm{TM}}$ Qontor $~(\mathrm{microspectrometer} \mathrm{equipped} \mathrm{with} \mathrm{a} \mathrm{confocal} \mathrm{microscope} \mathrm{and} \mathrm{an} \mathrm{Olympus} \mathrm{X50}$ objective (N.A = 0.55 ). It should be noted that nitrogen atmosphere was used to avoid exposure to oxygen. A $532 \mathrm{~nm}$ exciting radiation was used with a laser power below $0.05 \mathrm{~mW}$ for all samples to prevent their degradation. The spot area was of few $\mu \mathrm{m}^{2}$. Several locations were probed on each sample. The spectral resolution was about $4 \mathrm{~cm}^{-1}$ and the precision on the wavenumber was lower than $1 \mathrm{~cm}^{-1}$.

\subsubsection{SEM}

The analysis by Scanning Electron Microscopy (SEM) was performed on an JEOL JSM-IT500HR, with a Field Emission Gun (FEG). The powder sample was fixed on double face scotch tape. The analysis was made under high vacuum, and we settled a $60 \mu \mathrm{m}$ diaphragm aperture. The voltages for analysis came from $2 \mathrm{kV}$ to $5 \mathrm{kV}$. We used mainly the Secondary Electron Detector (SED) for imaging the powder.

\section{Results and discussion}

\subsection{Preparation of manganese hydroxide sulfate}

Figure 1 shows the evolution of the $\mathrm{pH}$ for increasing $\mathrm{R}=\frac{\mathrm{n}\left(\mathrm{OH}^{-}\right)}{\mathrm{n}\left(\mathrm{Mn}^{2+}\right)}$ ratio. With a $0.23 \mathrm{~mol} \cdot \mathrm{L}^{-1} \mathrm{Mn}^{2+}$ concentration after dilution, precipitation of pyrochroite $\mathrm{Mn}(\mathrm{OH})_{2}$ should start at $\mathrm{pH}=8$ [34] with the reaction described in equation 1 . For values up to $\mathrm{R}=1.48$ (A area), the $\mathrm{pH}$ follows a classical basic precipitation curve for nitrate, sulfate and chloride salts. For R above 1.48, the $\mathrm{pH}$ decreases for the solution with $\mathrm{MnSO}_{4}$ whereas it is following a classical titration pattern for the chloride and nitrate salts. A final increase shortly before $\mathrm{R}=2$ is observed for the three initial salts. During the addition of sodium hydroxide over the manganese solution, a white solid precipitates (SI fig. 16) for all R values. For all initial salt, the solid obtained for $\mathrm{R}=2$ is $\mathrm{Mn}(\mathrm{OH})_{2}$.

$$
\mathrm{Mn}^{2+}+2 \mathrm{OH}^{-} \rightarrow \mathrm{Mn}(\mathrm{OH})_{2}
$$

The distinctive behavior of $\mathrm{MnSO}_{4}$ solution for $\mathrm{R}<1.48$ may be attributed to the formation of manganese sulfate hydroxide basic salts. Indeed, various manganese sulfate hydroxide basic salts exist. The ratio between the hydroxide and the sulfate can be connected to a $\mathrm{R}$ value. Those salts are:

- $\mathrm{R}=0.75, \mathrm{Mn}_{3}(\mathrm{OH})_{2}\left(\mathrm{SO}_{4}\right)_{2}\left(\mathrm{H}_{2} \mathrm{O}\right)_{2}[35]$ and $\mathrm{Mn}_{3}(\mathrm{OH})_{2}\left(\mathrm{SO}_{4}\right)_{2}\left(\mathrm{H}_{2} \mathrm{O}\right)_{2} \cdot \mathrm{K}_{2} \mathrm{SO}_{4}$ [36]

- $\mathrm{R}=1, \mathrm{Mn}_{2}(\mathrm{OH})_{2} \mathrm{SO}_{4}$ [37]

- $\mathrm{R}=1.55, \mathrm{Mn}_{9}(\mathrm{OH})_{14}\left(\mathrm{SO}_{4}\right)_{2} \cdot \mathrm{H}_{2} \mathrm{O}[38,39]$

- $\mathrm{R}=1.6, \mathrm{Mn}_{5}(\mathrm{OH})_{8} \mathrm{SO}_{4}$ [40] 


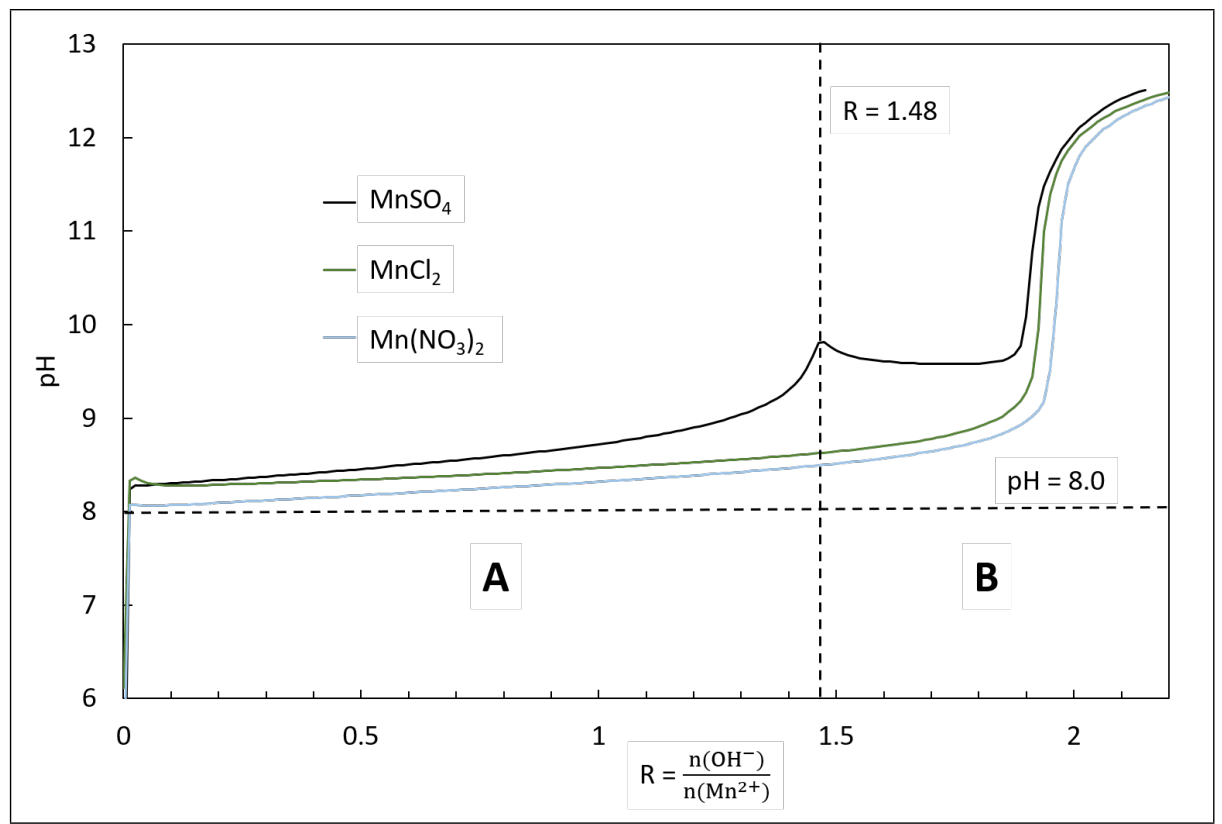

Figure 1: Evolution of the $\mathrm{pH}$ of $\mathrm{MnSO}_{4}, \mathrm{MnCl}_{2}$ and $\mathrm{Mn}\left(\mathrm{NO}_{3}\right)_{2}$ solution during sodium hydroxide addition

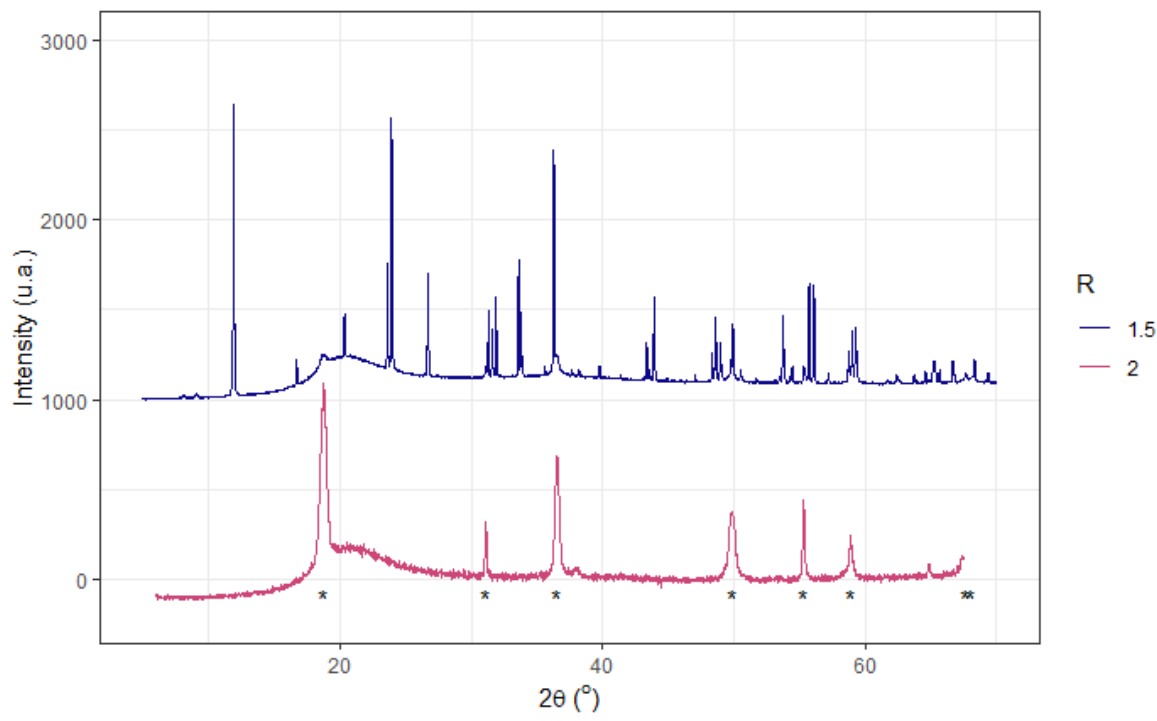

Figure 2: $\mathrm{XRD}$ of the solids using $\mathrm{MnSO}_{4}$ for various R ratios. Stars are the reference peaks for pyrochroite $\left(\mathrm{Mn}(\mathrm{OH})_{2}\right)$. The hump for $\theta=20^{\circ}$ is associated with the glycerol used to prevent the oxidation of the solid during the XRD analysis.

This solid is then transformed into manganese hydroxide as the $\mathrm{OH}^{-}$quantity is increased. Depending on the kinetics of the transformation, a decrease in the $\mathrm{pH}$ for increasing $\mathrm{OH}^{-}$amount can be explained by the spontaneous transformation of a metastable solid, similar to what is observed for the precipitation in supersaturated medium. [41].

Solids darken quickly, probably due to the air oxidation, even if no structure of oxidised product can be detected. Therefore, during XRD analysis, the solids are protected from the air by a glycerol film. For $\mathrm{R}=2$, the main product according to XRD is pyrochroite $\mathrm{Mn}(\mathrm{OH})_{2}$, in agreement with the ratio observed during titration. For $\mathrm{R}=1.5$, the diffractogram is more complex, and broad peaks of pyrochroite appear along shaper peaks. There is no match for the later with the ICDD database therefore, the formation of a solid with $1.5 \mathrm{OH}^{-}$ion per manganese cation is presumed, with the formula $\mathrm{Mn}_{4}(\mathrm{OH})_{6} \mathrm{SO}_{4}$, along with a small quantity of $\mathrm{Mn}(\mathrm{OH})_{2}$. Equation 2 describes this first precipitation from the $\left(\mathrm{Mn}^{2+}, \mathrm{SO}_{4}^{2-}\right)$ solution. 
The transformation of the XRD patterns between $\mathrm{R}=1.5$ and 2 on Figure 2 may explain why the pH curve shows a decreasing trend on Figure 1 . In this range, the transformation of a manganese basic sulfate salts unit into four $\mathrm{Mn}(\mathrm{OH})_{2}$ traps two hydroxide ions from the solution as shown on equation 3 . This explains the $\mathrm{pH}$ drop in the $\mathrm{R}=1.5-2$ range during $\mathrm{OH}^{-}$addition.

$$
\begin{gathered}
4 \mathrm{Mn}^{2+}+\mathrm{SO}_{4}^{2-}+6 \mathrm{OH}^{-} \rightarrow \mathrm{Mn}_{4}(\mathrm{OH})_{6} \mathrm{SO}_{4} \\
\mathrm{Mn}_{4}(\mathrm{OH})_{6} \mathrm{SO}_{4}+2 \mathrm{OH}^{-} \rightarrow 4 \mathrm{Mn}(\mathrm{OH})_{2}+\mathrm{SO}_{4}^{2-}
\end{gathered}
$$

A confirmation of the transformation in the solid eliminating sulfate during the addition are the ATR measurements of the damp solids after centrifugation. Figure 12 (SI) shows that in addition of the $\mathrm{O}-\mathrm{H}$ stretching and $\mathrm{H}_{2} \mathrm{O}$ bending modes, the $\mathrm{R}=1.5$ synthesis absorbs the IR light with two bands at 1059 and $1119 \mathrm{~cm}^{-1}$, which is typical for the sulfate ions [42]. This is not the case for the $\mathrm{R}=2$ synthesis. Precise characterization of the solid labelled "Mn $4(\mathrm{OH})_{6} \mathrm{SO}_{4}$ " is out of scope of this publication.

\subsection{Oxidation of manganese hydroxide sulfate}

As long as the solids obtained for various $\mathrm{R}$ with $\mathrm{MnSO}_{4}$ are kept under nitrogen bubbling, the suspensions remain white while their $\mathrm{pH}$ are stable within hours. To oxidise them, a $\mathrm{Na}_{2} \mathrm{~S}_{2} \mathrm{O}_{8}$ solution is added drop by drop. Subsequently, the solids are darkening and the $\mathrm{pH}$ decreases (SI Figure 15. The progress of the addition of $\mathrm{S}_{2} \mathrm{O}_{8}^{2-}$ in the solution is defined by the parameter $\mathrm{x}=2 \frac{\mathrm{n}\left(\mathrm{S}_{2} \mathrm{O}_{8}^{2-}\right)}{\mathrm{n}\left(\mathrm{Mn}^{2+}\right)}$. According to the stoichiometry of the oxidation reaction, if the reaction is complete, $\mathrm{x}$ is also equal to the fraction of the manganese with the $\mathrm{Mn}^{\mathrm{III}}$ valence in the $\mathrm{Mn}^{\mathrm{II}}$ and $\mathrm{Mn}^{\mathrm{III}}$ mixture as one persulfate accepts two electrons to produce sulfate ions.

For $\mathrm{R}=0$ (no addition of $\mathrm{OH}^{-}$), the $\mathrm{pH}$ slightly decreases from 4.0 to 3.6 between $\mathrm{x}=0$ and $\mathrm{x}=1$. There is no observable precipitation and only a small darkening of the color of the solution. This is in agreement with the fact that $\mathrm{Mn}^{2+}$ oxidation has to overcome a large free energy barrier [43].

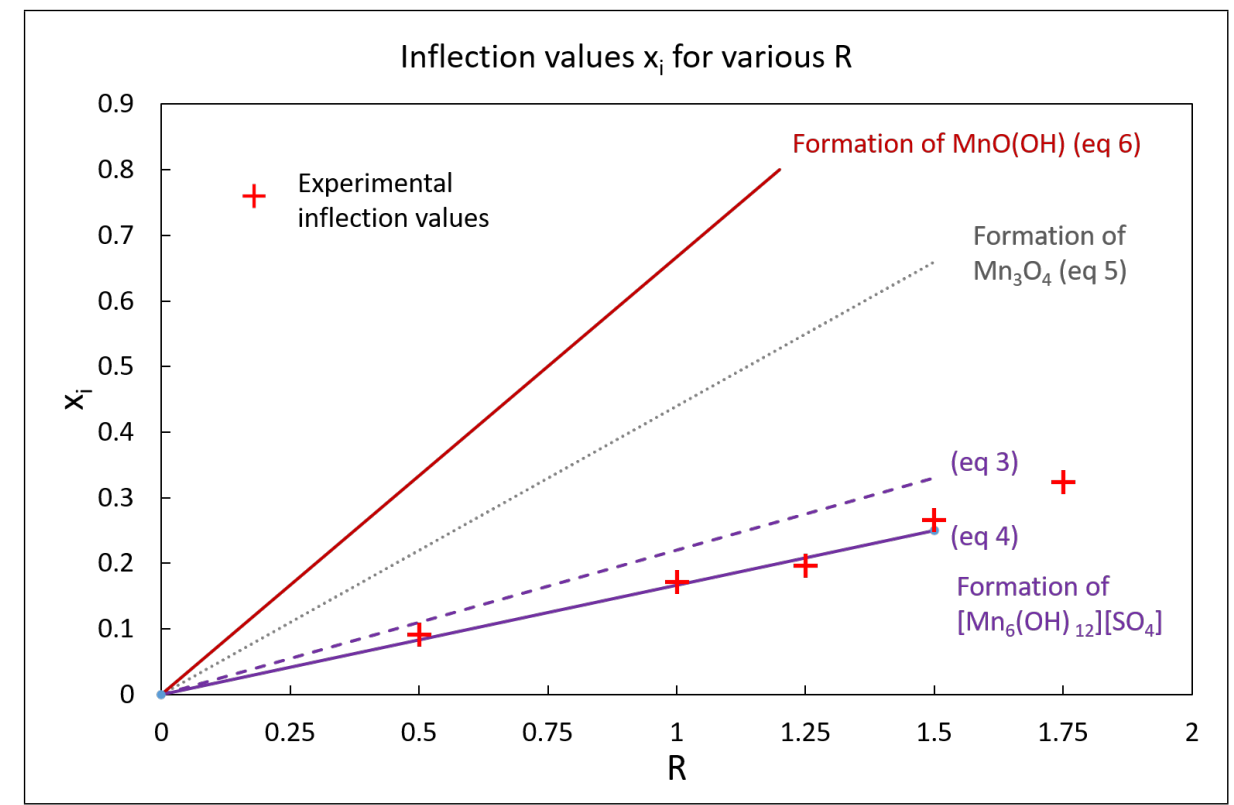

Figure 3: Position $\mathrm{x}_{\mathrm{i}}$ of the inflection (maximum of the derivative of the $\mathrm{pH}$ curve from SI Figure 15) as a function of the ratio $R$

For $\mathrm{R}$ between 0.5 and 1.75 , the variation of the $\mathrm{pH}$ against the $\mathrm{x}$ value presents an initial plateau whose length increases with $\mathrm{R}$ (Figure $15(\mathrm{SI})$ ). Let us define $\mathrm{x}_{\mathrm{i}}$ the length of the plateau as the position of the inflection. For $\mathrm{R}=2$, on the other side, there is no initial plateau. Figure 3 shows $\mathrm{x}_{\mathrm{i}}$ against $\mathrm{R}$. The inflexion of the $\mathrm{pH}$ curve occurs for $\mathrm{x}$ values proportional to the $\mathrm{R}$ ratio. 
Firstly, the oxidation of the initial basic salt is studied by comparing the $x_{i}$ value and what is expected with the stoichiometry of various possible transformation listed in equations 4.56 and 7 and represented with solid lines on Figure 3 .

1. Formation of a new type of LDH containing only Mn (Mn-LDH). With this equation, the $x_{i}$ value should be $x_{i}=2$ $\frac{\mathrm{n}_{\mathrm{S}} 4 \mathrm{O} 8}{\mathrm{n}_{\mathrm{M}} \mathrm{n}}=0.33$ for $\mathrm{R}=1.5$ as the manganese is fully precipitated. As the number of water molecule within the Mn-LDH structure is unknown, they will be omitted in the chemical formula of this LDH.

$$
3 \mathrm{Mn}_{4}^{\mathrm{II}}(\mathrm{OH})_{6} \mathrm{SO}_{4}+2 \mathrm{~S}_{2} \mathrm{O}_{8}^{2-}+6 \mathrm{OH}^{-} \rightarrow 2\left[\mathrm{Mn}_{4}^{\mathrm{II}} \mathrm{Mn}_{2}^{\mathrm{III}}(\mathrm{OH})_{12}\right]\left[\mathrm{SO}_{4}^{2-}\right]+5 \mathrm{SO}_{4}^{2-}
$$

2. The formation of the same product but simultaneously with a release of $\mathrm{Mn}^{2+}$ cations in the solution. The equation 5 describes this chemical reaction. As only one fourth of the initial manganese would be released during this transformation, the precipitation of $\mathrm{Mn}(\mathrm{OH})_{2}$ would not occur even with $\mathrm{pH}$ values above 8 , as what is observed for the less soluble $\mathrm{Fe}^{2+}$ ion [44]. According to the stoichiometry, the $\mathrm{x}_{\mathrm{i}}$ value for $\mathrm{R}=1.5$ should be $\mathrm{x}_{\mathrm{i}}=0.25$.

$$
2 \mathrm{Mn}_{4}^{\mathrm{II}}(\mathrm{OH})_{6} \mathrm{SO}_{4}+\mathrm{S}_{2} \mathrm{O}_{8}^{2-} \rightarrow\left[\mathrm{Mn}_{4}^{\mathrm{II}} \mathrm{Mn}_{2}^{\mathrm{III}}(\mathrm{OH})_{12}\right]\left[\mathrm{SO}_{4}^{2-}\right]+2 \mathrm{Mn}^{2+}+3 \mathrm{SO}_{4}^{2-}
$$

3. For the production of hausmannite, the $x_{i}$ value should be 0.66 for a $R$ value of 1.5 :

$$
3 \mathrm{Mn}_{4}^{\mathrm{II}}(\mathrm{OH})_{6} \mathrm{SO}_{4}+4 \mathrm{~S}_{2} \mathrm{O}_{8}^{2-}+14 \mathrm{OH}^{-} \rightarrow 4 \mathrm{Mn}^{\mathrm{II}} \mathrm{Mn}_{2}^{\mathrm{III}} \mathrm{O}_{4}+11 \mathrm{SO}_{4}^{2-}+16 \mathrm{H}_{2} \mathrm{O}
$$

4. And for the production of the various manganese(III) oxyhydroxide, the $x_{i}$ value should be 1 for $R=1.5$.

$$
\mathrm{Mn}_{4}^{\mathrm{II}}(\mathrm{OH})_{6} \mathrm{SO}_{4}+2 \mathrm{~S}_{2} \mathrm{O}_{8}^{2-}+6 \mathrm{OH}^{-} \rightarrow 4 \mathrm{Mn}^{\mathrm{III}} \mathrm{O}(\mathrm{OH})+5 \mathrm{SO}_{4}^{2-}+4 \mathrm{H}_{2} \mathrm{O}
$$

The ratio observed on Figure 3 between the $x_{i}$ values at the inflection and the $\mathrm{R}$ value suggest that the equation 5 is more likely. In addition, the $\mathrm{pH}$ drop from 9.8 to 8.5 from 0 to $\mathrm{x}_{\mathrm{i}}$ (Figure 16 indicates that $6.10^{-5} \mathrm{~mol}^{-\mathrm{L}^{-1}} \mathrm{OH}^{-}$react during the reaction, which is a small change in the concentration compared to the initial concentration of $\mathrm{Mn}^{2+} \mathrm{that}^{2}$ was equal to $0.23 \mathrm{~mol} . \mathrm{L}^{-1}$. The only equation that does not involve the consumption of $\mathrm{OH}^{-}$is equation 5

To confirm this hypothesis, the ratio $\mathrm{R}$ is now fixed at the value $\mathrm{R}=1.5$ with $\mathrm{MnSO}_{4}$ as the quantity of $\mathrm{Mn}_{4}(\mathrm{OH})_{6} \mathrm{SO}_{4}$ is maximised for this value. The solids for various $\mathrm{x}$ values will be extracted and characterized in the following sections.

\subsection{Synthesis of the Mn-LDH}

\subsection{1 pH and redox potential during the Mn-LDH synthesis}

Figure 4 indicates the $\mathrm{pH}$ and the potential $\mathrm{E}_{\mathrm{h}}$ for increasing $\mathrm{x}$ values during the addition of persulfate in a $\mathrm{R}=1.5$ $\mathrm{MnSO}_{4}$ solution. Three different zones can be observed:

- The A zone, in which the liquid get a light brown color, ended with an inflexion for $\mathrm{x}=0.266$. As mentioned in the previous section, this part can be attributed to the transformation of the basic salt into Mn-LDH according to the reaction 5

- The B zone, in which one can observe a pseudo-plateau for $\mathrm{E}_{\mathrm{h}}$ and $\mathrm{pH}$. This pseudo-plateau can be attributed to the transformation of $\mathrm{Mn}-\mathrm{LDH}$ into $\mathrm{MnO}(\mathrm{OH})$ as in:

$$
\left[\mathrm{Mn}_{4}^{\mathrm{II}} \mathrm{Mn}_{2}^{\mathrm{III}}(\mathrm{OH})_{12}\right]\left[\mathrm{SO}_{4}^{2-}\right]+\mathrm{S}_{2} \mathrm{O}_{8}^{2-}+\rightarrow 4 \mathrm{Mn}^{\mathrm{III}} \mathrm{O}(\mathrm{OH})+2 \mathrm{Mn}^{2+}+3 \mathrm{SO}_{4}^{2-}+4 \mathrm{H}_{2} \mathrm{O}
$$

It is interesting to note that the production of the fully oxidised Metal (III) oxyhydroxy species is also observed for further oxidation in the synthesis of Co [13] and Fe [44] monometallic LDH. However, the drop in the $\mathrm{pH}$ is observed for $\mathrm{x}$ values below 1 , which indicate that some of the $\mathrm{Mn}^{\mathrm{II}}$ species are not oxidised, which is in agreement with equations ?? and ??. Oxidation into $\mathrm{Mn}_{3} \mathrm{O}_{4}$ is also possible and are also in agreement with full transformation for $\mathrm{x}$ values below 1 .

- The $\mathrm{C}$ section, once the solid is fully transformed into $\mathrm{MnO}(\mathrm{OH}), \mathrm{Mn}_{3} \mathrm{O}_{4}$ and $\mathrm{Mn}_{(\mathrm{aq})}^{2+}$.

The attributions made in the previous list are only based on stoichiometric considerations. To study further those reactions, the solids were extracted from the solution in various zone and analysed. 


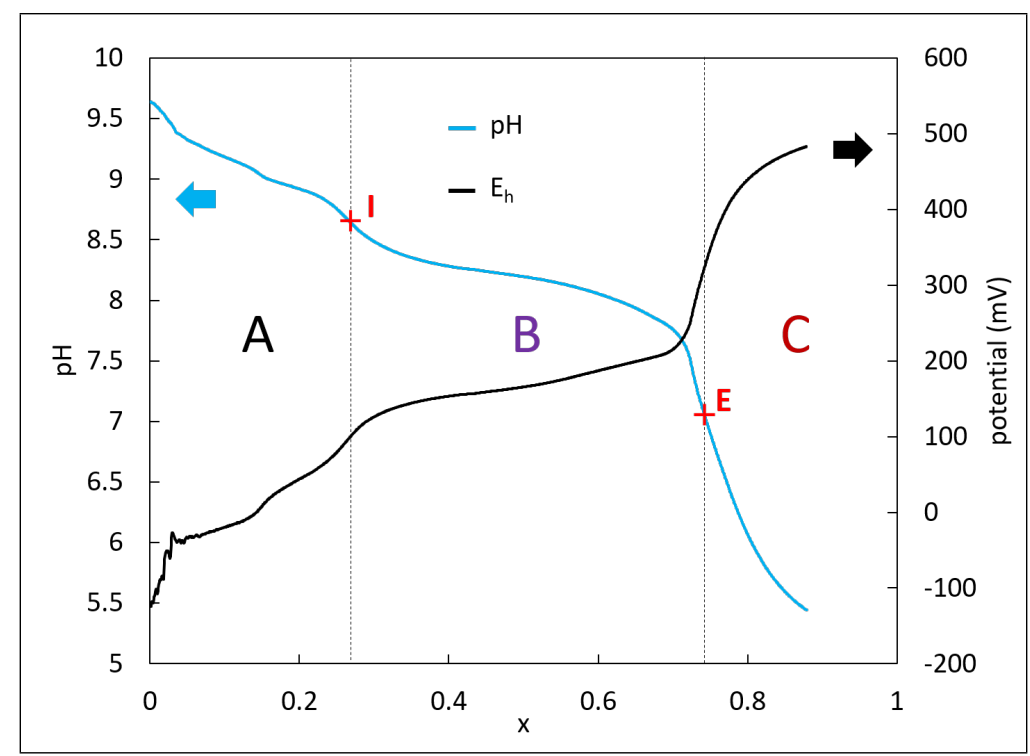

Figure 4: $\mathrm{pH}$ and $\mathrm{E}_{\mathrm{h}}$ values for a $\mathrm{MnSO}_{4}$ solution with $\mathrm{R}=1.5$ as a function of $\mathrm{x}$

\subsubsection{XRD characterization}

XRD of the solids obtained for $\mathrm{R}=1.5$ at various $\mathrm{x}$ values are plotted on Figure 5 .

The diffractogram for $\mathrm{x}=0$ is already described in Figure 2 and added here for comparison. It is interesting to note that the peak pattern attributed to a unknown solid for $\mathrm{x}=0$ cannot be observed for $\mathrm{x}=0.12$. On the other side, an another basic manganese salt, $\left(\mathrm{Mn}(\mathrm{OH})_{2}\right)_{7}\left(\mathrm{MnSO}_{4}\right)_{2} \cdot \mathrm{H}_{2} \mathrm{O}$, with the JCPDS file 00-018-0788 (stars on Figure 5 ) is observed. The $\mathrm{R}$ value for this structure according to its stoichiometry is 1.55 . It is possible that the solid produced for $\mathrm{x}=0$ is very similar to this solid. Alongside this structure, other diffraction peaks are present that can also be observed for $\mathrm{x}=$ 0.24 .

For the $\mathrm{x}=0.24$ diffractogram, all the peaks (except a weak one at about $18.4^{\circ}$ ) are indexed in the $\mathrm{P} \overline{3} 1 \mathrm{~m}$ hexagonal space group showing that the sample is pure as no unindexed peaks are observed (indexation is shown in SI on Figure 13 . This diffractogram is very similar to the one of the sulfate Fe-LDH (green rust) [45]. Furthermore the sample is fairly crystalline as shown by the sharpness of the peaks although the $(00 \ell)$ peaks are significantly broader as stacking faults are often present in LDH samples. Refined cell parameters for the pure manganese sample are $a=3.2270(7) \AA$ and $c=$ $10.9390(23) \AA$, these values are very close to the sulfate Fe-LDH (green rust) : $a=3.1793 \AA$ and $c=10.9664 \AA$ with the same space group. For Co-LDH, the parameters were $a=3.0468(9) \AA$ with carbonate as intercalated anion [46], for which the interlayer distance are much shorter (7.55 $\mathrm{\AA}$ ) and with R-3m space group.

A superstructure $\left(a=\sqrt{3} a_{0}\right)$ is observed for the Fe-LDH intercalated with $\mathrm{SO}_{4}^{2-}$ because of the ordering of the sulfate ions in the interlayer space [45]. In our $\mathrm{Mn}-\mathrm{LDH}$, this kind of superstructure can explain the additional peak at $2 \theta=18.4^{\circ}$ (the \# on Figure 5).

For $\mathrm{x}=1$, the diffractogram shows larger peaks that can be attributed to poorly crystalline manganite $\gamma-\mathrm{MnO}(\mathrm{OH})$ and groutite $\alpha-\mathrm{MnO}(\mathrm{OH})$.

\subsubsection{XPS characterization}

Surface properties of Mn-LDH were examined by XPS. Overview XPS spectra (not shown) show core-level photoelectron peaks around $169 \mathrm{eV}(\mathrm{S} 2 \mathrm{p}), 285 \mathrm{eV}(\mathrm{C} 1 \mathrm{~s}), 532 \mathrm{eV}(\mathrm{O} 1 \mathrm{~s}), 641 \mathrm{eV}\left(\mathrm{Mn} 2 \mathrm{p}_{3 / 2}\right), 652 \mathrm{eV}\left(\mathrm{Mn} 2 \mathrm{p}_{1 / 2}\right)$ and $1071 \mathrm{eV}$ (Na1s). The $\mathrm{C} 1 \mathrm{~s}$ peak should be attributed to atmospheric hydrocarbon contamination of the Mn-LDH surface. S2p high-resolution spectrum (not shown) presents $\mathrm{S} 2 \mathrm{p}_{3 / 2}$ and $\mathrm{S} 2 \mathrm{p}_{1 / 2}(168.5$ and $169.7 \mathrm{eV}$ ) components corresponding to sulfur in sulfate form. This signal may be attributed to sulfate in the interlayer space as well as from sulfate associated to sodium in adventitious $\mathrm{Na}_{2} \mathrm{SO}_{4}$.

On Figure 6, Mn2 $\mathrm{p}_{3 / 2}$ feature is the sum of the contributions of various Mn valence state. Due to coupling between the unpaired electron of the outer shell and unpaired core electron resulting from photoionization, high spin Mn ions 


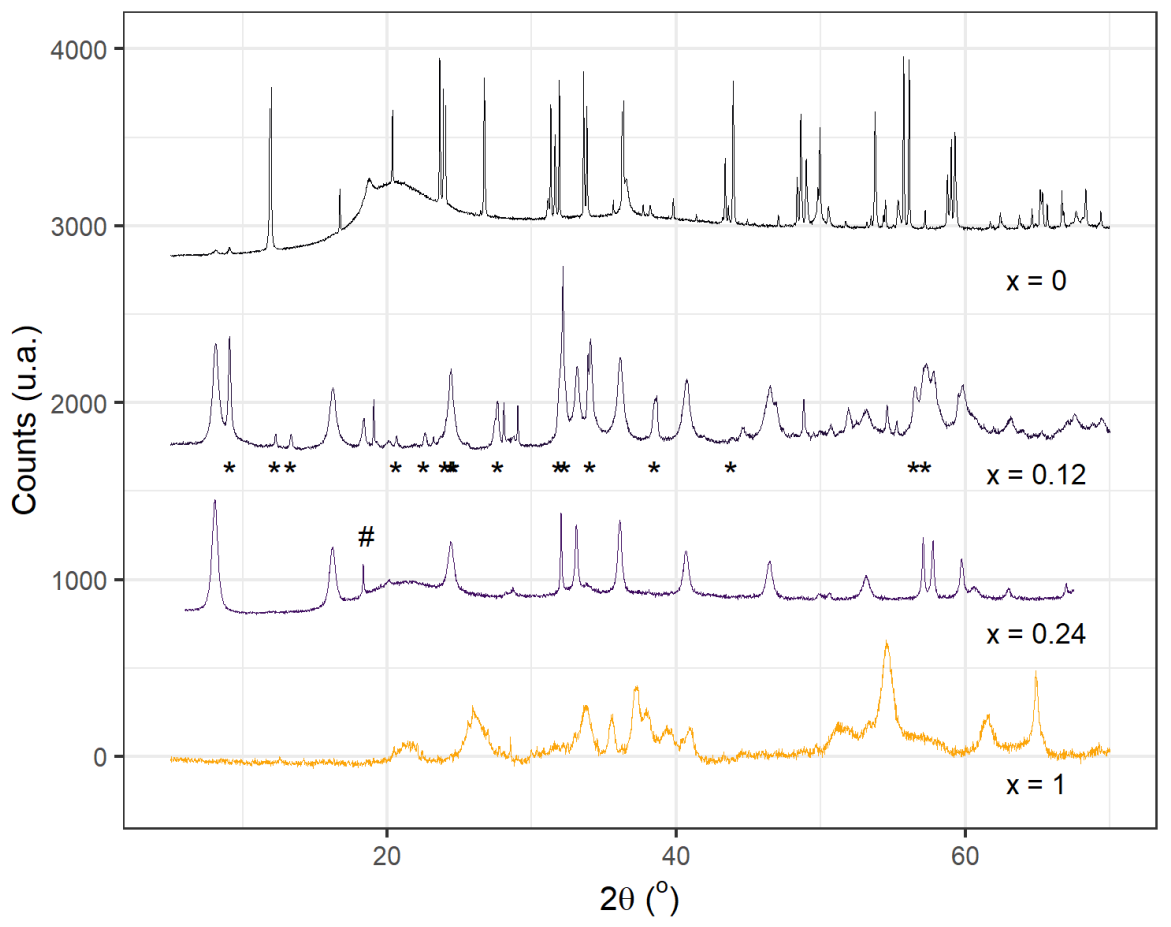

Figure 5: XRD of the solids for $\mathrm{R}=1.5$ with various $\mathrm{x}$ ratios. Stars are the main peaks for the $\left(\mathrm{Mn}(\mathrm{OH})_{2}\right)_{7}\left(\mathrm{MnSO}_{4}\right)_{2}$. $\mathrm{H}_{2} \mathrm{O}$ structure (JCPDS file 00-018-0788). \# indicate the additional peak due to a Mn-LDH superstructure
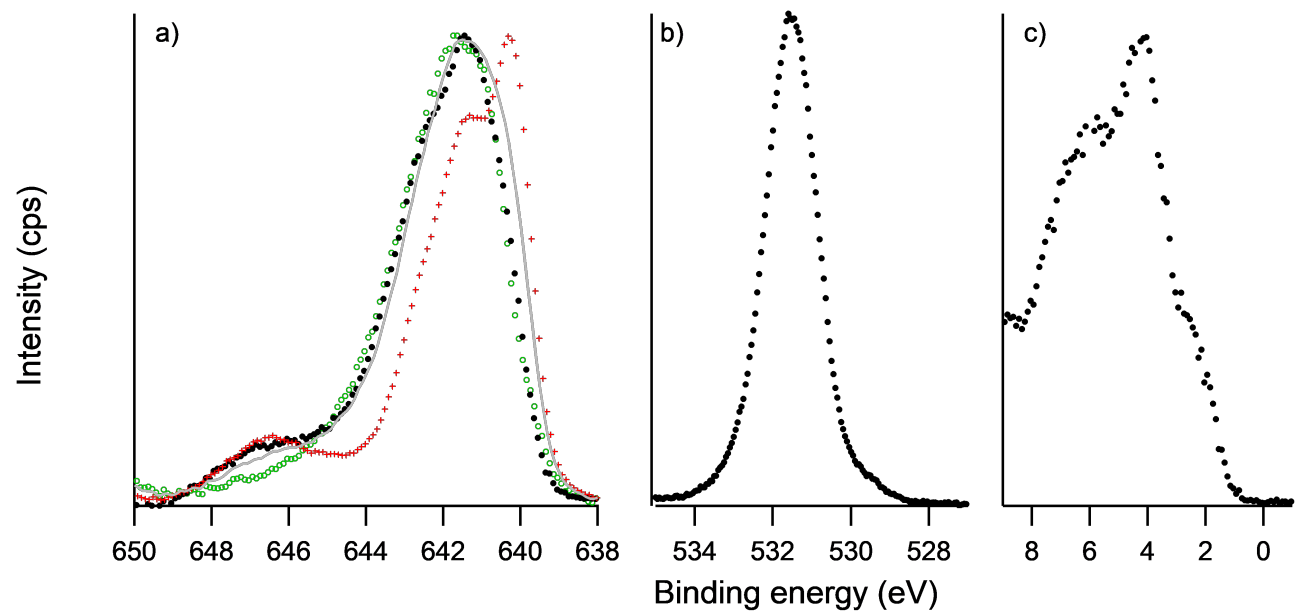

Figure 6: XPS of the solids for $\mathrm{R}=1.5$ and $\mathrm{x}=0.24$ ratios (black dots) in the $\mathrm{Mn} 2 \mathrm{p}_{3} / 2$ region (a), O1s region (b) and valence band (c). On the (a) graph, XPS spectra for $\mathrm{Mn}(\mathrm{OH})_{2}$ (red cross) and $\mathrm{x}=1$ (green open dots) as well as their combination (grey line) are plotted.

give rise to multiplet splitting. Overlapping of these multiplets poses serious difficulty for qualitative and quantitative analysis of Mn valence state [47, 48, 49, 50, 51, 52, 53, 54, 55, 56]. Figure 6 6 shows Mn2 $\mathrm{p}_{3 / 2}$ peak at $642.0 \mathrm{eV}$ with shoulder at $643 \mathrm{eV}$, which suggests the coexistence of $\mathrm{Mn}^{\mathrm{II}}$ and $\mathrm{Mn}^{\mathrm{III}}$ valence states. The shake-up satellite at 646 $\mathrm{eV}$ appears as the finger print of $\mathrm{Mn}(\mathrm{II})$ in $\mathrm{MnO}$ [48, 50, 49], $\mathrm{LDH}$ [52], or $\mathrm{Mn}(\mathrm{OH})_{2}$ as in Figure 6 To confirm this, the $\mathrm{Mn}_{2} \mathrm{p}_{3 / 2}$ spectra of $\mathrm{Mn}(\mathrm{OH})_{2}$ and $\mathrm{MnO}(\mathrm{OH})(\mathrm{Mn}(\mathrm{III}))$ as well as their linear combination with area ratio of 38:62 were added on Figure 6 a). The latter fairly reproduces the spectrum of Mn-LDH confirming the mixed-valence $\mathrm{Mn}(\mathrm{II}) / \mathrm{Mn}(\mathrm{III})$ nature of this compound. 


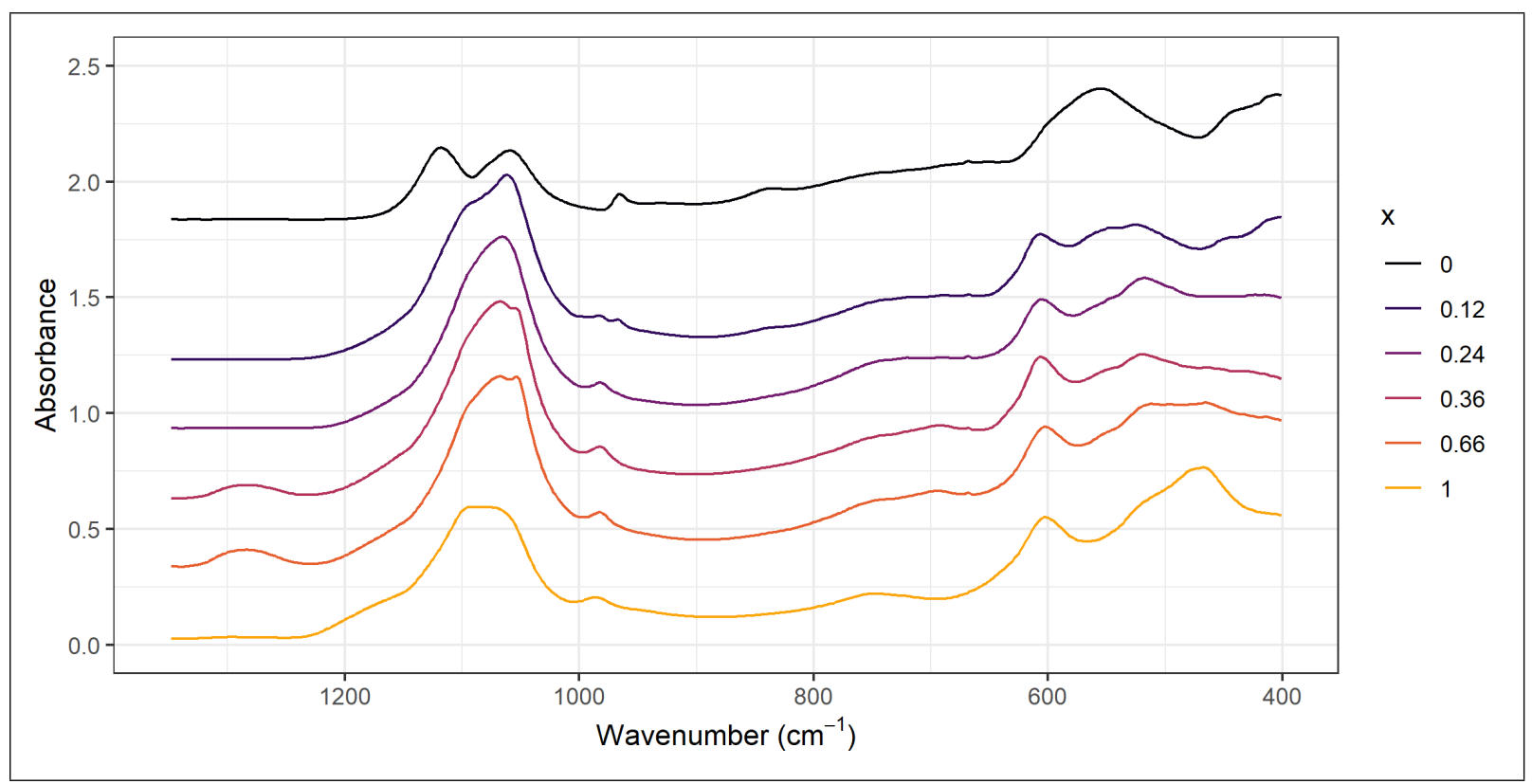

Figure 7: Infrared spectra for the $\mathrm{R}=1.5$ solid after various $\mathrm{x}$ addition of $\mathrm{S}_{2} \mathrm{O}_{8}^{2-}$

The $\mathrm{O} 1 \mathrm{~s}$ spectra (figure 6 presents a maximum at $531.4 \mathrm{eV}$ essentially attributed to hydroxyl species.

The valence band (VB) spectrum (figure 6) is dominated by a peak at $4.3 \mathrm{eV}$ with shoulders at 2.4 and $6.4 \mathrm{eV}$. The locations of these features are close to the ones reported for $\mathrm{MnO}$ or $\mathrm{Mn}_{2} \mathrm{O}_{3}$ [57, 58, 47]. The top of the $\mathrm{VB}$ (at 50\% of the low binding energy shoulder) is located around $1.7 \mathrm{eV}$ with respect to Fermi edge. Considering Mn ions in high-spin octahedral environment, photoemission signal at low binding energy might be due to $3 \mathrm{~d}$ electron removal from $e_{\mathrm{g}}$ and $\mathrm{t}_{2 \mathrm{~g}}$. The predict intensity ratio $3 / 2$ for $\mathrm{Mn}^{2+}$ ion is in the order of magnitude to what is observed for 2.4 and $4.3 \mathrm{eV}$ features. Nevertheless, overlap with $\mathrm{Mn}^{\mathrm{III}}$ contribution complicates the picture and further insight into VB interpretation would necessitate simulations [59] that are far beyond the scope of this work.

\subsubsection{Vibrational spectroscopies}

\section{Infrared}

Figure 7 gathers the IR spectra of the $\mathrm{R}=1.5$ solids after various $\mathrm{x}$. It is interesting to note that on the $\mathrm{x}=0$ spectrum, one can observe two main bands in the region for the $\nu_{3}$ vibration of sulfate $\left(1059\right.$ and $\left.1119 \mathrm{~cm}^{-1}\right)$. This split is similar as the one reported by Fan et al [40] for $\mathrm{Mn}_{5}(\mathrm{OH})_{8} \mathrm{SO}_{4}$ and can be explained by a anisotropic environment around the sulfate but may be also due to the presence of two different environments for the sulfate [42]. This split disappears at higher $x$ value and only one band at $1067 \mathrm{~cm}^{-1}$ is observed. At $\mathrm{x}=1$, the sulfate band can be attributed to sulfate associated to sodium in adventitious $\mathrm{Na}_{2} \mathrm{SO}_{4}$.

Beside this feature, another peak is changed during oxidation: an additional non attributed absorption band at $966 \mathrm{~cm}^{-1}$ disappears as $\mathrm{x}$ increases and a new band at $982 \mathrm{~cm}^{-1}$ appears. On the $\mathrm{x}=0.12$ spectrum, both can be seen, which confirm the fact that this solid is a mixture of two different products, as shown on Figure 5

For lower wavenumbers, a strict attribution of the peaks is not straightforward. The band at $555 \mathrm{~cm}^{-1}$ is in line with previous work by Fan et al as well as Salah et al observing a large band slightly above $500 \mathrm{~cm}^{-1}$ [40, 37] for $\mathrm{Mn}_{5}(\mathrm{OH})_{8} \mathrm{SO}_{4}$ and $\mathrm{Mn}_{2}(\mathrm{OH})_{2} \mathrm{SO}_{4}$ respectively. Then, the evolution of those peaks for increasing $\mathrm{x}$ shows the transformation of the solid during oxidation.

The same spectra but for higher wavenumbers on Figure 14 (SI) show the evolution of the O-H stretching during oxidation and the decrease of the absorbance in this region for the $\mathrm{x}=1$ product.

\section{Raman}




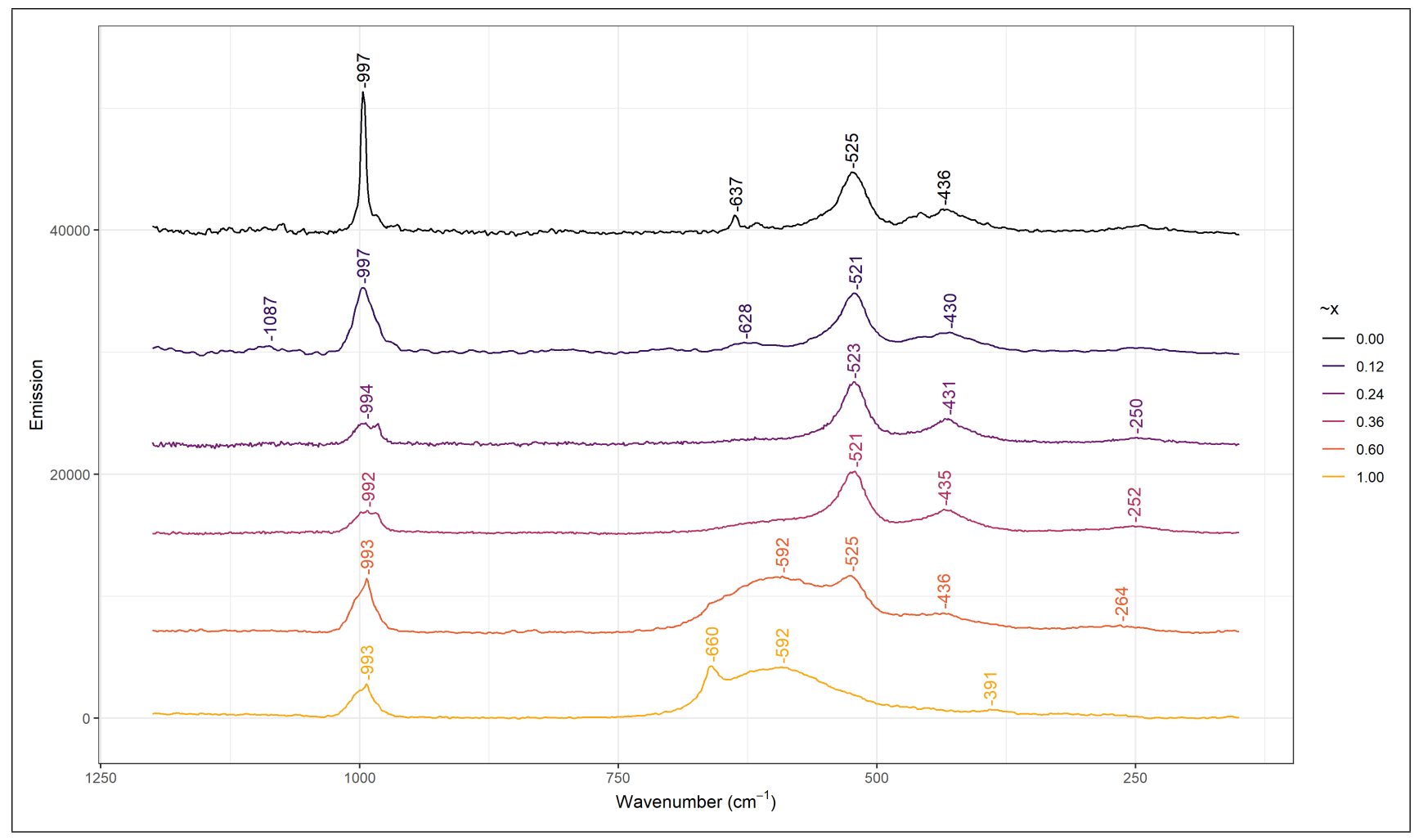

Figure 8: Raman for the $\mathrm{R}=1.5$ solid after various $\mathrm{x}$ addition of $\mathrm{S}_{2} \mathrm{O}_{8}^{2-}$

The evolution of Raman spectra for increasing $\mathrm{x}$ amount of persulfate is shown in Figure 8 . For the $\mathrm{x}=0$ spectrum, pyrochroite identified in XRD can be found with the $636 \mathrm{~cm}^{-1}$ peak, as referenced in the RRUFF database R10004 [60]. The other main peak at $525 \mathrm{~cm}^{-1}$ is probably related to the unknown manganese sulfate basic salt, as well as the sharp sulfate peak at $997 \mathrm{~cm}^{-1}$. For $\mathrm{x}=0.24$, two peaks at 431 and $522.5 \mathrm{~cm}^{-1}$ are observed, close to what is measured with the sulfate Fe-LDH (427 and $\left.518 \mathrm{~cm}^{-1}\right)$ [8], which suggest the presence of only one solid. As the oxidation continues, a broad peak centered around $580 \mathrm{~cm}^{-1}$ emerges. This peak can be attributed to the vibrations of the mixture of $\alpha-\mathrm{MnO}(\mathrm{OH})$ at $550 \mathrm{~cm}^{-1}[61]$ and $\gamma \mathrm{MnO}(\mathrm{OH})\left(558 \mathrm{~cm}^{-1}\right.$ for symmetric stretching of Mn-O-Mn bridge and $621 \mathrm{~cm}^{-1}$ for the asymmetric stretching of these bridge) [62]. It is noteworthy that the oxidation of the solid is not homogeneous and pure $\mathrm{LDH}$ as well as pure $\mathrm{MnO}(\mathrm{OH})$ spots can be found while translating the laser spot on the solid. The last spectrum for $\mathrm{x}=1$ shows no more vibration associated with the $\mathrm{LDH}$, and a new peak emerge at 660 $\mathrm{cm}^{-1}$ which can be attributed to $\mathrm{Mn}_{3} \mathrm{O}_{4}$, that was not observed in XRD [61].

Infrared and Raman spectroscopies confirm the transformation of the basic salt into the LDH followed by a subsequent oxidation into oxide and oxyde-hydoxide.

\subsubsection{Scanning Electron Microscopy}

Scanning Electron Microscopy was also used to characterize the solids. After oxidation, some ribbons structures can be seen, with $0.5 \mu \mathrm{m}$ width and a few $\mu \mathrm{m}$ length. This is different from what is observed with Fe [63] and Co-LDH [12], in which an hexagonal morphology was reported in SEM. The small roundish shapes of residual crystallites could be attributed to the part of the $\mathrm{LDH}$ oxidised into $\mathrm{Mn}_{3} \mathrm{O}_{4}$.

\subsubsection{Estimation of the standard Gibbs free energy of formation of the $\mathrm{Mn}^{\mathrm{II}}-\mathrm{Mn}^{\mathrm{III}} \mathrm{LDH}$}

The redox potential $\mathrm{E}_{\mathrm{h}}$ for the oxidation of $\mathrm{a}\left\{\mathrm{Fe}(\mathrm{OH})_{2}, \mathrm{Fe}_{\mathrm{aq}}^{\mathrm{II}}\right\}$ solution by the air was used to determine the standard Gibbs free energy of the Fe-LDH [44]. For example, a value $\Delta_{\mathrm{f}} \mathrm{G}^{0}(\mathrm{Fe}-\mathrm{LDH})=-3790 \pm 10 \mathrm{~kJ} \mathrm{~mol}^{-1}$ was determined by this method for Fe-LDH with sulfate in good agreement with other works [64]. Unfortunately, as the basic salt 


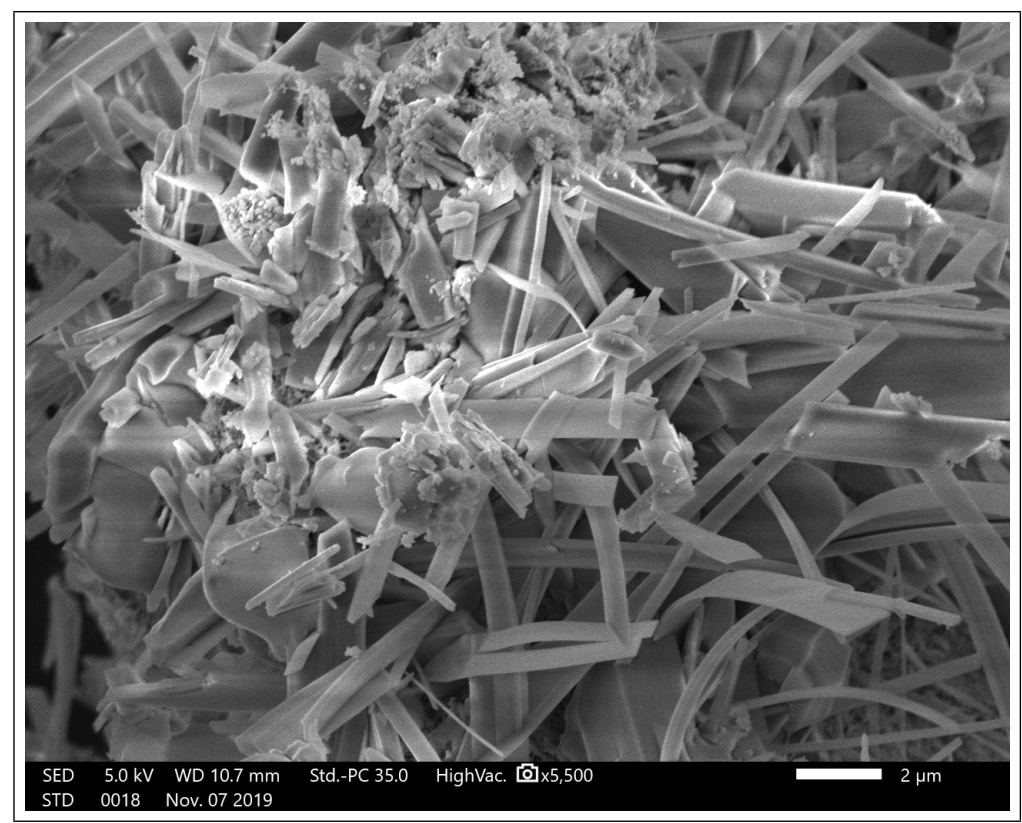

Figure 9: $\mathrm{SEM}$ images for the $\mathrm{R}=1.5$ solid after $(\mathrm{x}=0.24)$ addition of $\mathrm{S}_{2} \mathrm{O}_{8}^{2-}$. White bar in the lower right corner indicate the $2 \mu \mathrm{m}$ scale

" $\mathrm{Mn}_{4}(\mathrm{OH})_{6} \mathrm{SO}_{4}$ " produced for $\mathrm{R}=1.5$ before oxidation cannot be identified, the first step of oxidation (A part of Figure 4) transforming it into the Mn-LDH cannot be used to determine its standard Gibbs free energy of formation: $\Delta_{\mathrm{f}} \mathrm{G}^{0}(\mathrm{Mn}-\mathrm{LDH})$ value. On the contrary the redox potential values recorded in zone $\mathrm{B}(0.4<\mathrm{x}<0.7)$ was relatively constant and a pseudo $\mathrm{E}_{\mathrm{h}}$ plateau was observed. Zone $\mathrm{B}$ corresponds to the transformation of the Mn- $\mathrm{LDH}$ into $\mathrm{MnO}(\mathrm{OH})$, in fact a mixture of manganite $\gamma-\mathrm{MnO}(\mathrm{OH})$ and groutite $\alpha-\mathrm{MnO}(\mathrm{OH})$. The corresponding half reaction and Nernst equation are given in equation 9 and 10 , respectively:

$$
\begin{aligned}
& {\left[\mathrm{Mn}_{4}^{\mathrm{II}} \mathrm{Mn}_{2}^{\mathrm{III}}(\mathrm{OH})_{12}\right]\left[\mathrm{SO}_{4}^{2-}\right]_{(\mathrm{s})}+6 \mathrm{H}_{2} \mathrm{O}_{(\mathrm{l})} \rightleftharpoons 6 \mathrm{MnO}(\mathrm{OH})_{(\mathrm{s})}+\mathrm{SO}_{4}^{2-}(\mathrm{aq})+6 \mathrm{H}_{3} \mathrm{O}^{+}{ }_{(\mathrm{aq})}+4 \mathrm{e}^{-}}
\end{aligned}
$$

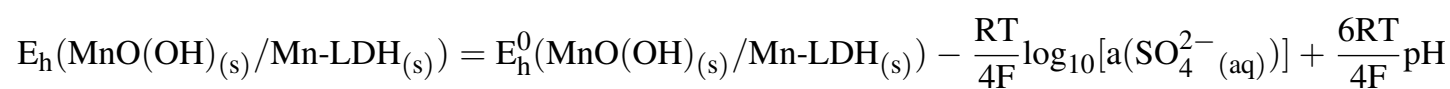

A value $\mathrm{E}_{\mathrm{h}}^{0}(\mathrm{MnO}(\mathrm{OH}) / \mathrm{Mn}-\mathrm{LDH})=+1.117 \mathrm{~V} / \mathrm{SHE}$ was computed from equation 10 by using the experimental $\mathrm{E}_{\mathrm{h}}$ value $(+380 \mathrm{mV})$ and $\mathrm{pH}$ value $(8.2)$ recorded at the middle of the $\mathrm{E}_{\mathrm{h}}$ plateau of zone B. In a first approximation the activity $\mathrm{a}\left(\mathrm{SO}_{4}\right)$ was assumed to be equal to the concentration of sulfate species. This concentration was estimated to be about 0.35 mol. $\mathrm{L}^{-1}$ at the middle of plateau $\mathrm{B}$, a value corresponding to the difference between the initial concentration of $\mathrm{SO}_{4}^{2-}$ in solution $\left(0.4 \mathrm{~mol} . \mathrm{L}^{-1}\right.$ ) and the quantity of sulfate incorporated into GRSO4 (about 0.05 mol. $\mathrm{L}^{-1}$ ). Taking into account the activity coefficient of sulfate species as performed in other works [44] will have only a minor influence on the computed values of $\mathrm{E}_{\mathrm{h}}^{0}$. The standard Gibbs energy of formation of the Mn-LDH was estimated by using equation 11

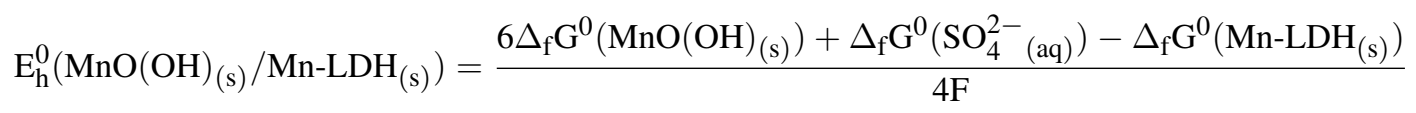

with $\mathrm{F}=96485 \mathrm{C} \cdot \mathrm{mol}^{-1}$ the Faraday constant. By using the $\Delta_{\mathrm{f}} \mathrm{G}^{0}$ values reported in SI table 1 , the standard Gibbs energy of formation of the $\mathrm{Mn}_{4}^{\mathrm{II}} \mathrm{Mn}_{2}^{\mathrm{III}}(\mathrm{OH})_{12} \mathrm{SO}_{4}$ was estimated to be comprised in between -4519 and $-4436 \mathrm{~kJ} \mathrm{~mol}^{-1}$, the lower and the higher values being determined for the final oxidation products manganite or groutite, respectively.

\subsubsection{Pourbaix Diagrams}

Pourbaix diagrams of Fe and Mn species were built by using the standard chemical potential of Table 1 (S.I.) and the Nernst equations of the relevant redox couples. The electrochemical equilibria were considered at room temperature ( $\mathrm{T}$ 


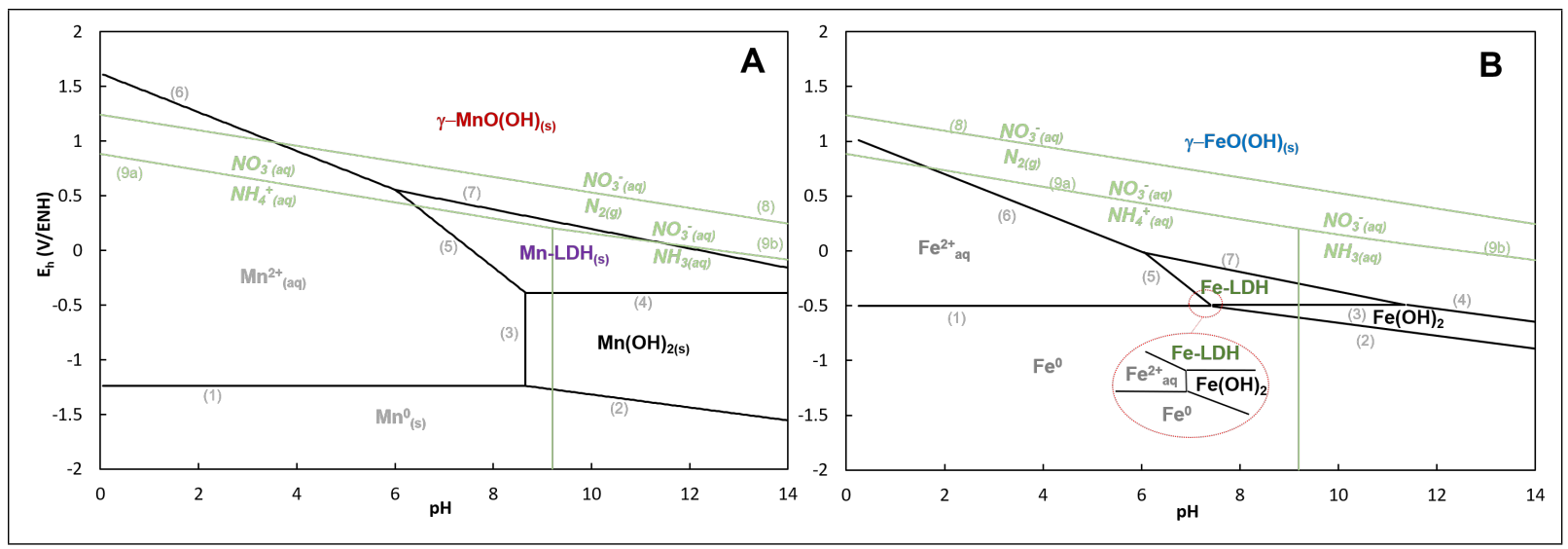

Figure 10: Pourbaix diagrams for Mn (A) and Fe (B)

$=298 \mathrm{~K})$ and the activities of the soluble species was fixed at $10^{-2} \cdot \mathrm{Mn}_{0(\mathrm{~s})}, \mathrm{Mn}_{(\mathrm{aq})}^{2+}, \mathrm{Mn}(\mathrm{OH})_{2(\mathrm{~s})}, \mathrm{Mn}_{-} \mathrm{LDH}_{(\mathrm{s})}$ and $\gamma-\mathrm{MnOOH}_{(\mathrm{s})}$ species were considered for the Mn Pourbaix diagram (Figure 10A). Basic salts with Mn mentioned in this study were not added as their thermodynamic properties are little known. Similarly, $\mathrm{Fe}_{0(\mathrm{~s})}, \mathrm{Fe}_{\mathrm{aq}}^{2+}, \mathrm{Fe}(\mathrm{OH})_{2(\mathrm{~s})}$, $\mathrm{Fe}-\mathrm{LDH}_{(\mathrm{s})}$ and $\gamma-\mathrm{FeOOH}_{(\mathrm{s})}$ species were considered for the drawing the Fe Pourbaix diagram (Figure 10B). The stability domains of $\mathrm{Mn}_{(\mathrm{aq})}^{2+}$ and $\mathrm{Mn}-\mathrm{LDH}_{(\mathrm{s})}$ are much broader than those of $\mathrm{Fe}_{(\mathrm{aq})}^{2+}$ and $\mathrm{Fe}-\mathrm{LDH}_{(\mathrm{s})}$. The relative stability of the Mn-LDH in comparison to Fe-LDH can also be illustrated by studying their potential reactivity towards nitrate species. For this purpose, the following $\mathrm{NO}_{3(\mathrm{aq})}^{-}$reduction reactions were considered:

$$
\begin{aligned}
& 2 \mathrm{NO}_{3(\mathrm{aq})}^{-}+10 \mathrm{e}^{-}+12 \mathrm{H}_{3} \mathrm{O}_{(\mathrm{aq})}^{+}=\mathrm{N}_{2(\mathrm{~g})}+18 \mathrm{H}_{2} \mathrm{O}_{(\mathrm{l})} \\
& \mathrm{NO}_{3(\mathrm{aq})}^{-}+8 \mathrm{e}^{-}+10 \mathrm{H}_{3} \mathrm{O}_{(\mathrm{aq})}^{+}=\mathrm{NH}_{4(\mathrm{aq})}^{+}+13 \mathrm{H}_{2} \mathrm{O}_{(\mathrm{l})} \\
& \mathrm{NO}_{3(\mathrm{aq})}^{-}+8 \mathrm{e}^{-}+9 \mathrm{H}_{3} \mathrm{O}_{(\mathrm{aq})}^{+}=\mathrm{NH}_{3(\mathrm{aq})}+12 \mathrm{H}_{2} \mathrm{O}_{(\mathrm{l})}
\end{aligned}
$$

The corresponding Nernst equations computed for $\mathrm{T}=298 \mathrm{~K}$ are the following :

$$
\mathrm{E}_{\mathrm{h}}\left(\mathrm{NO}_{3(\mathrm{aq})}^{-} / \mathrm{N}_{2(\mathrm{~g})}\right)=\mathrm{E}_{\mathrm{h}}^{0}\left(\mathrm{NO}_{3(\mathrm{aq})}^{-} / \mathrm{N}_{2(\mathrm{~g})}\right)+\frac{\mathrm{RT}^{10 \mathrm{~F}}}{\log }\left[\frac{\mathrm{a}\left(\mathrm{NO}_{3(\mathrm{aq})}^{-}\right)^{2}}{\mathrm{a}\left(\mathrm{N}_{2(\mathrm{~g})}\right)}\right]-\frac{12 \mathrm{RT}}{10 \mathrm{~F}} \mathrm{pH}
$$

For equation 12 with $\mathrm{E}_{\mathrm{h}}^{0}\left(\mathrm{NO}_{3(\mathrm{aq})}^{-} / \mathrm{N}_{2(\mathrm{~g})}\right)=1.24 \mathrm{~V} / \mathrm{SHE}$ and $\mathrm{a}\left(\mathrm{N}_{2(\mathrm{~g})}\right)=1, \mathrm{a}\left(\mathrm{NO}_{3(\mathrm{aq})}^{-}\right)=0.01$.

$$
\mathrm{E}_{\mathrm{h}}\left(\mathrm{NO}_{3(\mathrm{aq})}^{-} / \mathrm{NH}_{4(\mathrm{aq})}^{+}\right)=\mathrm{E}_{\mathrm{h}}^{0}\left(\mathrm{NO}_{3(\mathrm{aq})}^{-} / \mathrm{NH}_{4(\mathrm{aq})}^{+}\right)+\frac{\mathrm{RT}}{8 \mathrm{~F}} \log _{10}\left[\frac{\mathrm{a}\left(\mathrm{NO}_{3(\mathrm{aq})}^{-}\right)}{\mathrm{a}\left(\mathrm{NH}_{4(\mathrm{aq})}^{+}\right)}\right]-\frac{10 \mathrm{RT}}{8 \mathrm{~F}} \mathrm{pH}
$$

For equation 13 with $\mathrm{E}_{\mathrm{h}}^{0}\left(\mathrm{NO}_{3(\mathrm{aq})}^{-} / \mathrm{NH}_{4(\mathrm{aq})^{+}}\right)=0.88 \mathrm{~V} / \mathrm{SHE}$ and $\mathrm{a}\left(\mathrm{NO}_{3(\mathrm{aq})}^{-}\right)=\mathrm{a}\left(\mathrm{NH}_{4(\mathrm{aq})}^{+}\right)=0.01$.

$$
\mathrm{E}_{\mathrm{h}}\left(\mathrm{NO}_{3(\mathrm{aq})}^{-} / \mathrm{NH}_{3(\mathrm{aq})}\right)=\mathrm{E}_{\mathrm{h}}^{0}\left(\mathrm{NO}_{3(\mathrm{aq})}^{-} / \mathrm{NH}_{3(\mathrm{aq})}\right)+\frac{\mathrm{RT}}{8 \mathrm{~F}} \log _{10}\left[\frac{\mathrm{a}\left(\mathrm{NO}_{3(\mathrm{aq})}^{-}\right)}{\mathrm{a}\left(\mathrm{NH}_{3(\mathrm{aq})}\right)}\right]-\frac{9 \mathrm{RT}}{8 \mathrm{~F}} \mathrm{pH}
$$

For equation 14 with $\mathrm{E}_{\mathrm{h}}^{0}\left(\mathrm{NO}_{3(\mathrm{aq})}^{-} / \mathrm{NH}_{3(\mathrm{aq})}\right)=0.81 \mathrm{~V} / \mathrm{SHE}$ and $\mathrm{a}\left(\mathrm{NO}_{3(\mathrm{aq})}^{-}\right)=\mathrm{a}\left(\mathrm{NH}_{4(\mathrm{aq})}^{+}\right)=0.01$.

Equations 15,16 and 17 were superimposed on the Pourbaix diagrams and correspond to lines $8,9 \mathrm{a}$ and $9 \mathrm{~b}$, respectively (Figure 10p. As observed on Figure $10 \mathrm{~B}$, lines 8, 9a\&b are situated well above line 7 corresponding to the Fe-LDH/ $\gamma$ $\mathrm{FeOOH}$ redox couple. Therefore the reaction of reduction of nitrate into either ammonium or dinitrogen by oxidizing 


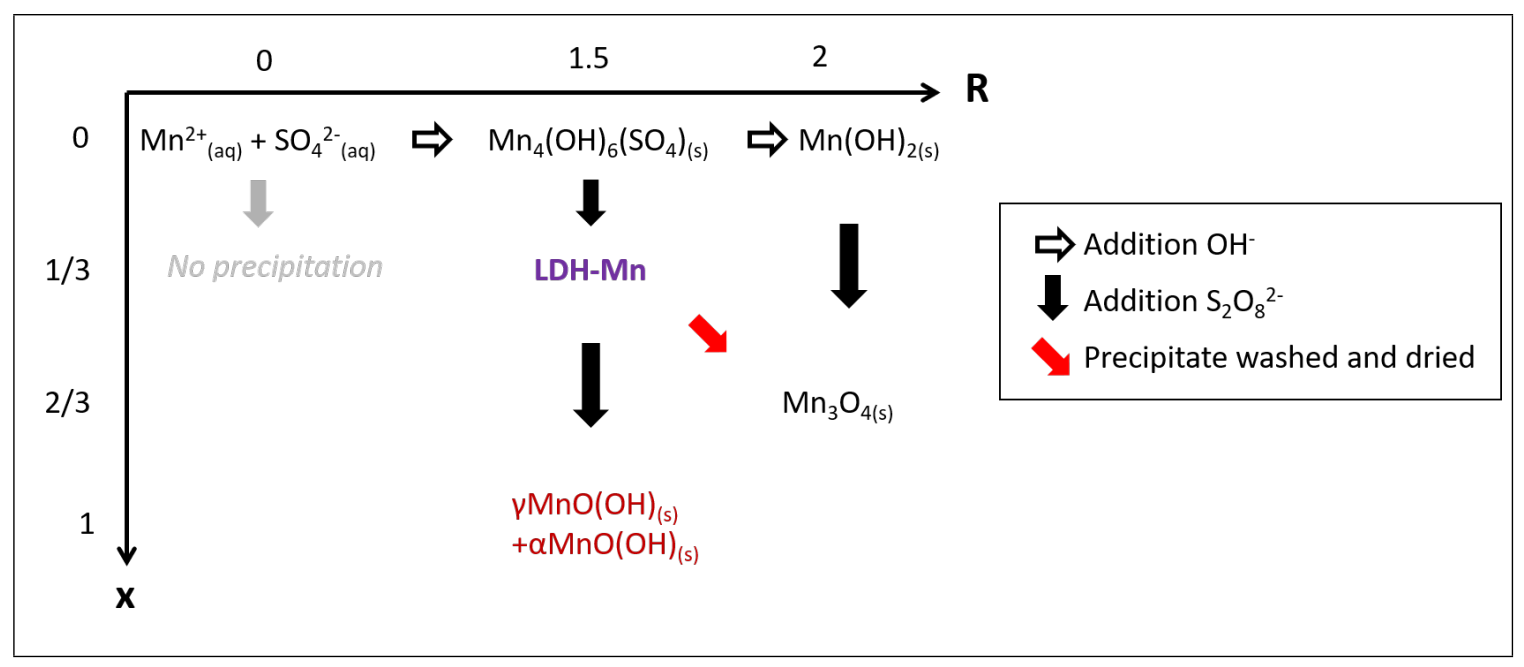

Figure 11: Summary of the structures observed in this study

the $\mathrm{Fe}-\mathrm{LDH}$ into $\gamma-\mathrm{FeO}(\mathrm{OH})$ is thermodynamically favorable. Previously performed experiments are in agreement with such a prediction and the Fe-LDH was observed to reduce nitrate either in ammonium [10] for sulfate and chloride containing Fe-LDH or into a mixture of ammonium and $\mathrm{N}$-gaseous species for carbonate containing LDH [65]. Interestingly, lines 8 is still situated above line 7 on the Mn-Pourbaix diagram (Figure 10A), while it is not the case for line $9 \mathrm{a} \& \mathrm{~b}$. This means that the $\mathrm{Mn}-\mathrm{LDH}$ is not reactive enough to reduce nitrate into ammonium but it may potentially reduce nitrate into $\mathrm{N}_{2}$. This is in line with what is observed with the manganese assisted denitrification process observed by Swathi et al. [66]. This last reaction is of upmost importance if the goal is to find a material useful for a water denitrification process. Such a properties could be unique among the monometallic LDH family. Indeed, the $\mathrm{Fe}-\mathrm{LDH}$ is a too strong reductant that transform nitrate mainly into the more reduced form of nitrogen, i.e. $\mathrm{NH}_{4}^{+}$. On the contrary, Co-LDH and Ni-LDH could be too weak reductants to transform $\mathrm{NH}_{4}^{+}$into $\mathrm{N}_{2}$. Such a preliminary forecast can be proposed by comparing similar redox potential, e.g. the standard potentials $\mathrm{E}_{\mathrm{h}}^{0}$ of $\mathrm{M}_{(\mathrm{aq})}^{2+} / \mathrm{M}_{2}^{\mathrm{III}} \mathrm{O}_{3}$ redox couples are equal to $0.728,1.443,1.746$ and $1.753 \mathrm{~V} / \mathrm{SHE}$ when $\mathrm{M}=\mathrm{Fe}, \mathrm{Mn}, \mathrm{Co}$ and Ni, respectively [67]. However, further experiments dedicated to the determination of the standard chemical potential of Co-LDH and Ni-LDH and to the reactivity of monometallic LDH towards nitrate species should be explored to confirm these assumptions.

\section{Conclusion}

A new monometallic manganese double layered hydroxide was discovered using a basic $\mathrm{Mn}^{\mathrm{II}}$ salt (probably $\mathrm{Mn}_{4}(\mathrm{OH})_{6} \mathrm{SO}_{4}$ ) and then oxidising it with $\mathrm{S}_{2} \mathrm{O}_{8}^{2-}$ as recapitulated on Figure 11 . Measurement of the $\mathrm{pH}$ and the redox potential show that $\mathrm{a} x=0.24$ ratio of the persulfate oxidant is necessary to produce this solid. XRD and Raman confirm this transformation. XPS shows that the solid contain a mixture of $\mathrm{Mn}^{\mathrm{II}}$ and $\mathrm{Mn}^{\mathrm{III}}$. SEM shows an ribbon shape organisation of the solid.

Pourbaix diagrams calculated from the experimental measurements during the synthesis indicate that this solid is theoretically able to reduce nitrate into dinitrogen without further reduction into ammonium or ammonia. This indicates that this solid could be used for water remediation. Finally, the eventual formation of Mn-LDH in natural environment should also be considered. Indeed, fougerite, the equivalent solid using iron, is already identified in hydromorphic soils and groundwater. MnII-MnIII LDH could be an intermediate species in the oxidation of manganese.

\section{Acknowledgment}

The authors thank Martine Mallet for her help for the XPS analysis. 


\section{References}

[1] Zhengyang Cai, Xiuming Bu, Ping Wang, Johnny C. Ho, Junhe Yang, and Xianying Wang. Recent advances in layered double hydroxide electrocatalysts for the oxygen evolution reaction. Journal of Materials Chemistry A, 7(10):5069-5089, March 2019.

[2] Guanhua Zhang, Xueqiang Zhang, Yue Meng, Guoxiang Pan, Zheming Ni, and Shengjie Xia. Layered double hydroxides-based photocatalysts and visible-light driven photodegradation of organic pollutants: A review. Chemical Engineering Journal, 392:123684, July 2020.

[3] Mukarram Zubair, Muhammad Daud, Gordon McKay, Farrukh Shehzad, and Mamdouh A. Al-Harthi. Recent progress in layered double hydroxides (LDH)-containing hybrids as adsorbents for water remediation. Applied Clay Science, 143:279-292, July 2017.

[4] Yaswanth Kuthati, Ranjith Kumar Kankala, and Chia-Hung Lee. Layered double hydroxide nanoparticles for biomedical applications: Current status and recent prospects. Applied Clay Science, 112-113:100-116, August 2015.

[5] M. V. Bukhtiyarova. A review on effect of synthesis conditions on the formation of layered double hydroxides. Journal of Solid State Chemistry, 269:494-506, January 2019.

[6] W. Feitknecht and G. Keller. Über Die dunkelgrünen Hydroxyverbindungen des Eisens. Zeitschrift für anorganische Chemie, 262(1-5):61-68, 1950.

[7] J. D. Bernal, D. R. Dasgupta, and A. L. Mackay. The oxides and hydroxides of iron and their structural inter-relationships. Clay Minerals Bulletin, 4(21):15-30, August 1959.

[8] F. Trolard, J. M. R. Génin, M. Abdelmoula, G. Bourrié, B. Humbert, and A. Herbillon. Identification of a green rust mineral in a reductomorphic soil by Mossbauer and Raman spectroscopies. Geochimica et Cosmochimica Acta, 61(5):1107-1111, March 1997.

[9] C. Ruby, A. Géhin, R. Aissa, and J. M. R. Génin. Mass-balance and Eh-pH diagrams of FeII-III green rust in aqueous sulphated solution. Corrosion Science, 48(11):3824-3837, November 2006.

[10] Hans Chr. B. Hansen, Christian B. Koch, Hanne Nancke-Krogh, Ole K. Borggaard, and Jan Sørensen. Abiotic Nitrate Reduction to Ammonium: Key Role of Green Rust. Environmental Science \& Technology, 30(6):20532056, May 1996.

[11] Z. P Xu and H. C Zeng. A new approach for design and synthesis of CoII and CoII,III hydroxide materials. International Journal of Inorganic Materials, 2(2):187-196, June 2000.

[12] Renzhi Ma, Kazunori Takada, Katsutoshi Fukuda, Nobuo Iyi, Yoshio Bando, and Takayoshi Sasaki. Topochemical Synthesis of Monometallic (Co2+-Co3+) Layered Double Hydroxide and Its Exfoliation into Positively Charged $\mathrm{Co}(\mathrm{OH}) 2$ Nanosheets. Angewandte Chemie, 120(1):92-95, 2008.

[13] Pierre Vialat, Pierre Rabu, Christine Mousty, and Fabrice Leroux. Insight of an easy topochemical oxidative reaction in obtaining high performance electrochemical capacitor based on CoIICoIII monometallic cobalt Layered Double Hydroxide. Journal of Power Sources, 293:1-10, October 2015.

[14] Ting Ye, Weimin Huang, Liming Zeng, Mengli Li, and Jianlin Shi. CeO2-x platelet from monometallic cerium layered double hydroxides and its photocatalytic reduction of CO2. Applied Catalysis B: Environmental, 210:141148, August 2017.

[15] Jianbo Liang, Renzhi Ma, Fengxia Geng, Yasuo Ebina, and Takayoshi Sasaki. Ln2(OH)4SO4·nH2O $(\mathrm{Ln}=\mathrm{Pr}$ to Tb; n 2): A New Family of Layered Rare-Earth Hydroxides Rigidly Pillared by Sulfate Ions. Chemistry of Materials, 22(21):6001-6007, November 2010. Publisher: American Chemical Society.

[16] Feng Gu, Xing Cheng, Shufen Wang, Xu Wang, and Pooi See Lee. Oxidative Intercalation for Monometallic Ni2+Ni3+ Layered Double Hydroxide and Enhanced Capacitance in Exfoliated Nanosheets. Small, 11(17):2044-2050, 2015.

[17] Laure-Marie Grand, Sara J. Palmer, and Ray L. Frost. Synthesis and thermal stability of hydrotalcites containing manganese. Journal of Thermal Analysis and Calorimetry, 100(3):981-985, June 2010.

[18] Tiago Coelho, Renan Micha, Santiago Arias, Yordy E. Licea, Luz Amparo Palacio, and Arnaldo C. Faro. Influence of the $\mathrm{Mg} 2+$ or $\mathrm{Mn} 2+$ contents on the structure of $\mathrm{NiMnAl}$ and $\mathrm{CoMgAl}$ hydrotalcite materials with high aluminum contents. Catalysis Today, 250:87-94, July 2015.

[19] Chengxue Yang, Libing Liao, Guocheng Lv, Limei Wu, Lefu Mei, and Zhaohui Li. Synthesis and characterization of Mn intercalated Mg-Al hydrotalcite. Journal of Colloid and Interface Science, 479:115-120, October 2016. 
[20] Samiran Bhattacharjee and JamesA. Anderson. Novel Chiral Sulphonato-Salen-Manganese(III)-Pillared Hydrotalcite Catalysts for the Asymmetric Epoxidation of Styrenes and Cyclic Alkenes. Advanced Synthesis \& Catalysis, 348(1-2):151-158, January 2006.

[21] Yiyun Du, Qian Wang, Xiao Liang, Yufei He, Junting Feng, and Dianqing Li. Hydrotalcite-like MgMnTi non-precious-metal catalyst for solvent-free selective oxidation of alcohols. Journal of Catalysis, 331:154-161, November 2015.

[22] José M. Fernandez, Cristobalina Barriga, Maria-Angeles Ulibarri, Francisco M. Labajos, and Vicente Rives. Preparation and thermal stability of manganese-containing hydrotalcite, [Mg0.75MnII0.04MnIII0.21(OH)2](CO3)0.11·nH2O. Journal of Materials Chemistry, 4(7):1117-1121, January 1994.

[23] Hani Farhat, Christine Taviot-Gueho, Guillaume Monier, Valérie Briois, Claude Forano, and Christine Mousty. Insights into the Structure and the Electrochemical Reactivity of Cobalt-Manganese Layered Double Hydroxides: Application to H2O2 Sensing. The Journal of Physical Chemistry C, 124(28):15585-15599, July 2020. Publisher: American Chemical Society.

[24] Zita Timár, Gábor Varga, Szabolcs Muráth, Zoltán Kónya, Ákos Kukovecz, Viktor Havasi, Albert Oszkó, István Pálinkó, and Pál Sipos. Synthesis, characterization and photocatalytic activity of crystalline $\mathrm{Mn}$ (II)Cr(III)-layered double hydroxide. Catalysis Today, 284:195-201, April 2017.

[25] Yudi Ruan, Xiaodai Jia, Chao Wang, Wenyao Zhen, and Xiue Jiang. Mn-Fe layered double hydroxide nanosheets: a new photothermal nanocarrier for O2-evolving phototherapy. Chemical Communications, 54(83):11729-11732, October 2018.

[26] Fang Song and Xile Hu. Ultrathin Cobalt-Manganese Layered Double Hydroxide Is an Efficient Oxygen Evolution Catalyst. Journal of the American Chemical Society, 136(47):16481-16484, November 2014. Publisher: American Chemical Society.

[27] Xiufei Zhao, Chenggang Niu, Lei Zhang, Hai Guo, Xiaoju Wen, Chao Liang, and Guangming Zeng. Co-Mn layered double hydroxide as an effective heterogeneous catalyst for degradation of organic dyes by activation of peroxymonosulfate. Chemosphere, 204:11-21, August 2018.

[28] Ruiqi Li, Yuqian Liu, Haobo Li, Man Zhang, Yiran Lu, Lin Zhang, Jianping Xiao, Frank Boehm, and Kai Yan. One-Step Synthesis of NiMn-Layered Double Hydroxide Nanosheets Efficient for Water Oxidation. Small Methods, 3(1):1800344, 2019.

[29] Xiaoliang Wang, Huiyan Yan, Jiaqi Zhang, Xiaodong Hong, Shaobin Yang, Chao Wang, and Zhi Li. Stamenpetal-like $\mathrm{CeO} 2 / \mathrm{NiMn}$ layered double hydroxides composite for high-rate-performance supercapacitor. Journal of Alloys and Compounds, 810:151911, November 2019.

[30] R. Scholder and H. Kyri. Über die Oxydation von Mangan(II)-hydroxyd mit Sauerstoff in konzentrierten Laugen. Zeitschrift für anorganische und allgemeine Chemie, 270(1-4):56-68, 1952.

[31] Hella Boumaiza, Romain Coustel, Ghouti Medjahdi, Christian Ruby, and Latifa Bergaoui. Conditions for the formation of pure birnessite during the oxidation of $\mathrm{Mn}$ (II) cations in aqueous alkaline medium. Journal of Solid State Chemistry, 248:18-25, April 2017.

[32] C. J. Matocha, P. Dhakal, and S. M. Pyzola. Chapter Four - The Role of Abiotic and Coupled Biotic/Abiotic Mineral Controlled Redox Processes in Nitrate Reduction. In Donald L. Sparks, editor, Advances in Agronomy, volume 115, pages 181-214. Academic Press, January 2012.

[33] Colleen M. Hansel. Chapter Two - Manganese in Marine Microbiology. In Robert K. Poole, editor, Advances in Microbial Physiology, volume 70 of Microbiology of Metal Ions, pages 37-83. Academic Press, January 2017.

[34] CRC Handbook of Chemistry and Physics, 87th ed Editor-in-Chief: David R. Lide (National Institute of Standards and Technology). CRC Press/Taylor and Francis Group: Boca Raton, FL. 2006. 2608 pp. \$139.95. ISBN 0-84930487-3. Journal of the American Chemical Society, 129(3):724-724, January 2007.

[35] Mohsen Ben Salah, Serge Vilminot, Gilles André, Mireille Richard-Plouet, Françoise Bourée-Vigneron, Tahar Mhiri, and Mohamedally Kurmoo. Synthesis, Nuclear, and Magnetic Structures and Magnetic Properties of [Mn3(OH)2(SO4)2(H2O)2]. Chemistry - A European Journal, 10(8):2048-2057, 2004.

[36] Jie-Hui Yu, Ling Ye, Hong Ding, Yan Chen, Qin Hou, Xiao Zhang, and Ji-Qing Xu. Structural characterization of a layered double salt $\mathrm{Mn} 3(\mathrm{OH}) 2(\mathrm{SO} 4) 2(\mathrm{H} 2 \mathrm{O}) 2 \cdot \mathrm{K} 2 \mathrm{SO} 4$. Inorganic Chemistry Communications, 10(2):159-162, February 2007.

[37] Mohsen Ben Salah, Serge Vilminot, Tahar Mhiri, and Mohamedally Kurmoo. Synthesis, Crystal Structure, and Magnetic Properties of Mn2(OH)2SO4: A Novel Layered Hydroxide. European Journal of Inorganic Chemistry, 2004(11):2272-2276, 2004. 
[38] Xuejin Zhang, Youming Li, Lijun Wang, Lizheng Sha, and Zhijun Hu. Investigation of manganese hydrolysis particles and decomposition of hydrogen peroxide in the pulp bleaching process. Nordic Pulp \& Paper Research Journal, 30(4):578-583, 2015.

[39] Huifang Zhao, Haibiao Wu, Haowei Hu, Yan Li, Jing Li, and Xuejin Zhang. Cooperative Decomposition of Hydrogen Peroxide by Lignin-combined Transition Metals in Pulp Bleaching. BioResources, 13(2):3922-3931, April 2018.

[40] Yong Fan, Guang Hua Li, Lei Yang, Zhi Ming Zhang, Yan Chen, Tian You Song, and Shou Hua Feng. Synthesis, Crystal Structure, and Magnetic Properties of a Three-Dimensional Hydroxide Sulfate: Mn5(OH)8SO4. European Journal of Inorganic Chemistry, 2005(16):3359-3364, 2005.

[41] Yi-Ling Hsieh, Grace A. Ilevbare, Bernard Van Eerdenbrugh, Karl J. Box, Manuel Vincente Sanchez-Felix, and Lynne S. Taylor. pH-Induced Precipitation Behavior of Weakly Basic Compounds: Determination of Extent and Duration of Supersaturation Using Potentiometric Titration and Correlation to Solid State Properties. Pharmaceutical Research, 29(10):2738-2753, October 2012.

[42] Melissa D. Lane. Mid-infrared emission spectroscopy of sulfate and sulfate-bearing minerals. American Mineralogist, 92(1):1-18, January 2007.

[43] Seonyi Namgung, Chul-Min Chon, and Giehyeon Lee. Formation of diverse Mn oxides: a review of bio/geochemical processes of Mn oxidation. Geosciences Journal, 22(2):373-381, April 2018.

[44] P. Refait, C. Bon, L. Simon, G. Bourrie, F. Trolard, J. Bessiere, and J. M. R. Genin. Chemical composition and Gibbs standard free energy of formation of $\mathrm{Fe}(\mathrm{II})-\mathrm{Fe}(\mathrm{III})$ hydroxysulphate green rust and $\mathrm{Fe}(\mathrm{II})$ hydroxide. Clay Minerals, 34(3):499-510, September 1999.

[45] Lilian Simon, Michel François, Philippe Refait, Guillaume Renaudin, Michèle Lelaurain, and Jean-Marie R Génin. Structure of the Fe(II-III) layered double hydroxysulphate green rust two from Rietveld analysis. Solid State Sciences, 5(2):327-334, February 2003.

[46] Pierre Vialat, Christine Mousty, Christine Taviot-Gueho, Guillaume Renaudin, Herve Martinez, Jean-Charles Dupin, Erik Elkaim, and Fabrice Leroux. High-Performing Monometallic Cobalt Layered Double Hydroxide Supercapacitor with Defined Local Structure. Advanced Functional Materials, 24(30):4831-4842, 2014.

[47] Ahmad Ali Audi and Peter M. A. Sherwood. Valence-band x-ray photoelectron spectroscopic studies of manganese and its oxides interpreted by cluster and band structure calculations. Surface and Interface Analysis, 33(3):274-282, 2002.

[48] Eugene S. Ilton, Jeffrey E. Post, Peter J. Heaney, Florence T. Ling, and Sebastien N. Kerisit. XPS determination of Mn oxidation states in Mn (hydr)oxides. Applied Surface Science, 366:475-485, March 2016.

[49] Mark C. Biesinger, Brad P. Payne, Andrew P. Grosvenor, Leo W. M. Lau, Andrea R. Gerson, and Roger St. C. Smart. Resolving surface chemical states in XPS analysis of first row transition metals, oxides and hydroxides: Cr, Mn, Fe, Co and Ni. Applied Surface Science, 257(7):2717-2730, January 2011.

[50] H. W. Nesbitt and D. Banerjee. Interpretation of XPS Mn(2p) spectra of Mn oxyhydroxides and constraints on the mechanism of MnO 2 precipitation. American Mineralogist, 83(3-4):305-315, April 1998.

[51] Haesung Jung and Young-Shin Jun. Ionic Strength-Controlled Mn (Hydr)oxide Nanoparticle Nucleation on Quartz: Effect of Aqueous Mn(OH)2. Environmental Science \& Technology, 50(1):105-113, January 2016.

[52] Muhammad Asif, Wang Haitao, Dong Shuang, Ayesha Aziz, Guoan Zhang, Fei Xiao, and Hongfang Liu. Metal oxide intercalated layered double hydroxide nanosphere: With enhanced electrocatalyic activity towards $\mathrm{H} 2 \mathrm{O} 2$ for biological applications. Sensors and Actuators B: Chemical, 239:243-252, February 2017.

[53] Jamiu O. Eniola, Rajeev Kumar, Awad A. Al-Rashdi, Mohammad Omaish Ansari, and Mohamed A. Barakat. Fabrication of Novel $\mathrm{Al}(\mathrm{OH}) 3 / \mathrm{CuMnAl}$-Layered Double Hydroxide for Detoxification of Organic Contaminants from Aqueous Solution. ACS Omega, 4(19):18268-18278, November 2019.

[54] Stephan Werner, Vincent Wing-hei Lau, Stephan Hug, Viola Duppel, Hauke Clausen-Schaumann, and Bettina V. Lotsch. Cationically Charged MnIIAlIII LDH Nanosheets by Chemical Exfoliation and Their Use As Building Blocks in Graphene Oxide-Based Materials. Langmuir, 29(29):9199-9207, July 2013.

[55] Tie Li, Jian Wang, Yan Xu, Yudong Cao, Hongzhen Lin, and Ting Zhang. Hierarchical Structure Formation and Effect Mechanism of Ni/Mn Layered Double Hydroxides Microspheres with Large-Scale Production for Flexible Asymmetric Supercapacitors. ACS Applied Energy Materials, 1(5):2242-2253, May 2018.

[56] Alexandr N. Simonov, Rosalie K. Hocking, Lizhi Tao, Thomas Gengenbach, Timothy Williams, Xi-Ya Fang, Hannah J. King, Shannon A. Bonke, Dijon A. Hoogeveen, Christine A. Romano, Bradley M. Tebo, Lisandra L. Martin, William H. Casey, and Leone Spiccia. Tunable Biogenic Manganese Oxides. Chemistry - A European Journal, 23(54):13482-13492, September 2017. 
[57] J. van Elp, R. H. Potze, H. Eskes, R. Berger, and G. A. Sawatzky. Electronic structure of MnO. Physical Review $B, 44(4): 1530-1537$, July 1991.

[58] Asish K. Kundu, Sukanta Barman, and Krishnakumar S. R. Menon. Effects of film thickness and magnetism on the electronic structure of MnO films. Physical Review B, 96(19):195116, November 2017.

[59] C. Franchini, R. Podloucky, J. Paier, M. Marsman, and G. Kresse. Ground-state properties of multivalent manganese oxides: Density functional and hybrid density functional calculations. Physical Review B, 75(19):195128, May 2007.

[60] Barbara Lafuente, R. T. Downs, H. Yang, and N. Stone. 1. The power of databases: The RRUFF project. De Gruyter, November 2015.

[61] Biao Hu, Kailiang Lu, Qing Zhang, Xiaobo Ji, and Wencong Lu. Data mining assisted materials design of layered double hydroxide with desired specific surface area. Computational Materials Science, 136:29-35, August 2017.

[62] Paul F. Smith, Benjamin J. Deibert, Shivam Kaushik, Graeme Gardner, Shinjae Hwang, Hao Wang, Jafar F. AlSharab, Eric Garfunkel, Laura Fabris, Jing Li, and G. Charles Dismukes. Coordination Geometry and Oxidation State Requirements of Corner-Sharing MnO6 Octahedra for Water Oxidation Catalysis: An Investigation of Manganite (-MnOOH). ACS Catalysis, 6(3):2089-2099, March 2016. Publisher: American Chemical Society.

[63] Imad A. M. Ahmed, Liane G. Benning, Gabriella Kakonyi, Aryani D. Sumoondur, Nick J. Terrill, and Samuel Shaw. Formation of Green Rust Sulfate: A Combined in Situ Time-Resolved X-ray Scattering and Electrochemical Study. Langmuir, 26(9):6593-6603, May 2010.

[64] Karina Barbara Ayala-Luis, Christian Bender Koch, and Hans Christian Bruun Hansen. THE STANDARD GIBBS ENERGY OF FORMATION OF Fe(II)Fe(III) HYDROXIDE SULFATE GREEN RUST. Clays and Clay Minerals, 56(6):633-644, December 2008.

[65] Marjorie Etique, Asfaw Zegeye, Brian Grégoire, Cédric Carteret, and Christian Ruby. Nitrate reduction by mixed iron(II-III) hydroxycarbonate green rust in the presence of phosphate anions: The key parameters influencing the ammonium selectivity. Water Research, 62:29-39, October 2014.

[66] Desireddy Swathi, P. C. Sabumon, and Shihabudheen M. Maliyekkal. Microbial mediated anoxic nitrificationdenitrification in the presence of nanoscale oxides of manganese. International Biodeterioration \& Biodegradation, 119:499-510, April 2017.

[67] J Van Muylder and M Pourbaix. Atlas d'équilibres électrochimiques à 25 C. Gauthier-Villars \& Cie, Paris, page 378, 1963.

[68] A. J. Bard, R. Parsons, and J. Jordan. Standard potentials in aqueous solution. January 1985.

[69] Owen Bricker. Some stability relations in the system $\mathrm{Mn}-\mathrm{O} 2-\mathrm{H} 2 \mathrm{O}$ at 25 and one atmosphere total pressure. American Mineralogist, 50(9):1296-1354, September 1965.

[70] John D. Hem and Carol J. Lind. Nonequilibrium models for predicting forms of precipitated manganese oxides. Geochimica et Cosmochimica Acta, 47(11):2037-2046, November 1983.

\section{Supplementary information}

\subsection{Characterization of the basic salts}

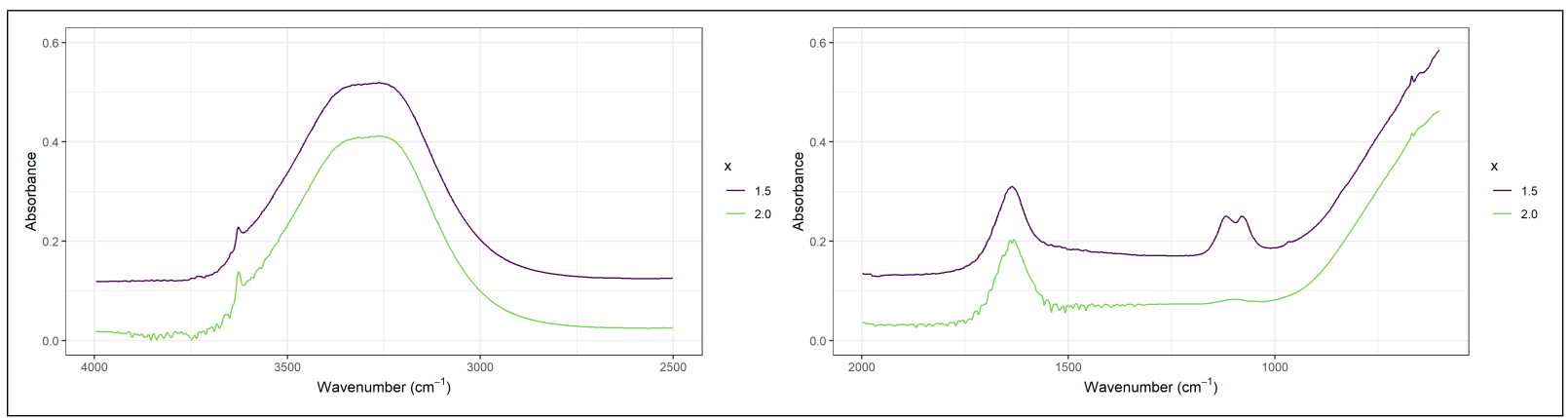

Figure 12: IR spectra of the solids obtained with a $\mathrm{Mn}^{2+}$ solution and a $\mathrm{NaOH}$ addition with various $\mathrm{R}$ 


\subsection{Further characterization of the Mn-LDH}

\subsubsection{XRD of the Mn-LDH with peak indexation}

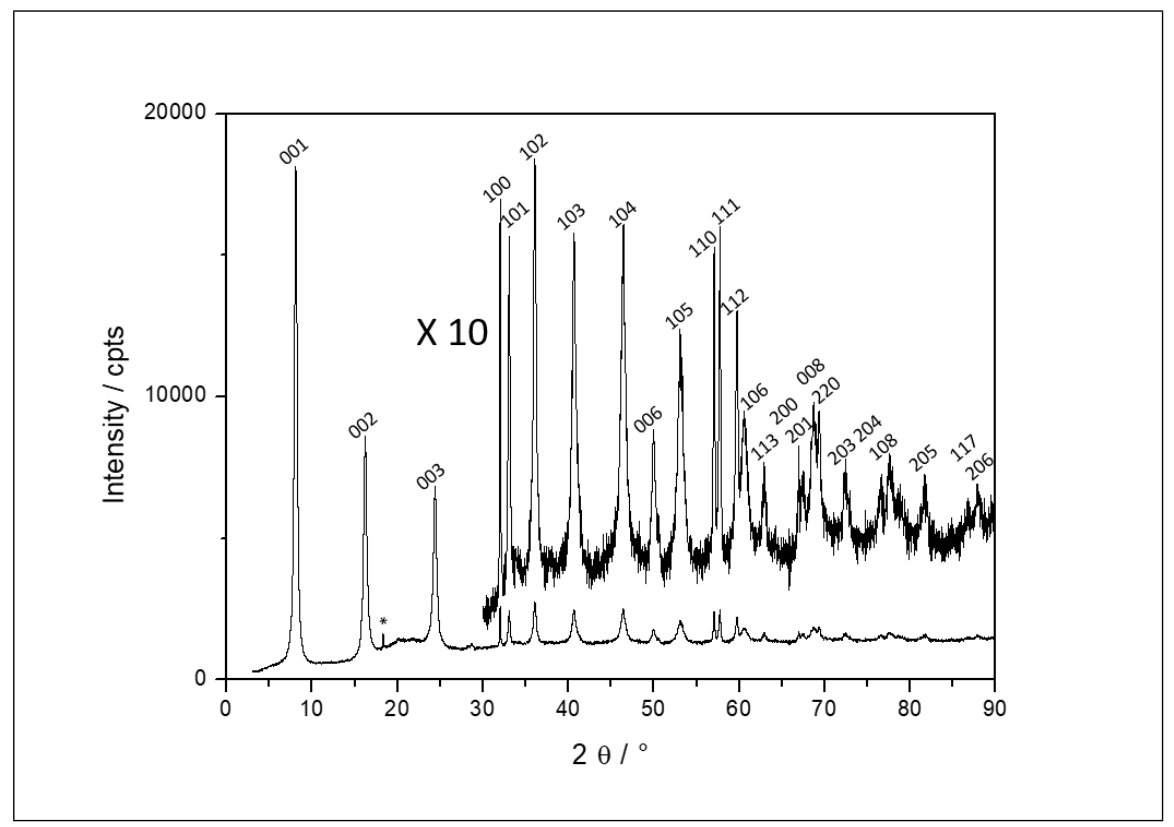

Figure 13: XRD with peak indexation of the Mn-LDH

\subsubsection{IR measurement of the Mn-LDH}

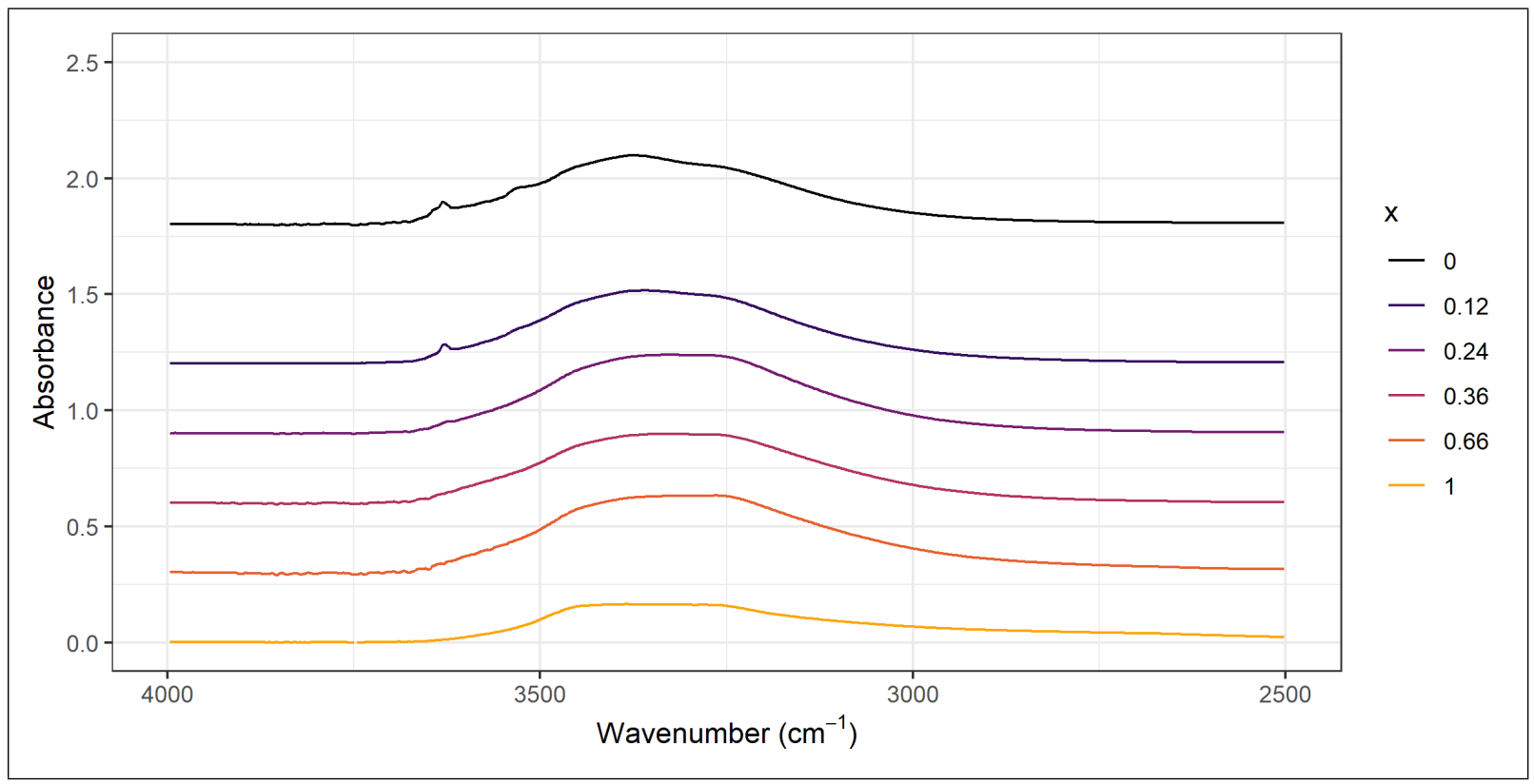

Figure 14: $\mathrm{OH}$ stretching region of the Mn-LDH 


\subsection{Thermodynamic data used in this work}

\begin{tabular}{|c|c|c|}
\hline Species & $\Delta_{\mathrm{f}} \mathrm{G}^{0}\left(\mathrm{~kJ} \cdot \mathrm{mol}^{-1}\right)$ & Reference \\
\hline $\mathrm{H}_{2} \mathrm{O}_{(1)}$ & -237.19 & [68] \\
\hline $\mathrm{SO}_{4(\mathrm{ag})}^{2-}$ & -744.56 & [68] \\
\hline $\mathrm{NO}_{3(\mathrm{aq})}^{-}$ & -110.58 & 67] \\
\hline $\mathrm{NH}_{4(\mathrm{aq})}^{+}$ & -79.5 & 67] \\
\hline $\mathrm{NH}_{3(\mathrm{aq})}$ & -26.6 & [68] \\
\hline $\mathrm{Fe}^{2+}$ & -84.93 & 67 \\
\hline $\mathrm{Fe}(\mathrm{OH})_{2}$ & -483.55 & 67 \\
\hline $\mathrm{Fe}_{4}^{\mathrm{II}} \mathrm{Fe}_{2}^{\mathrm{III}}(\mathrm{OH})_{12} \mathrm{SO}_{4}$ & -3790 & [44] \\
\hline $\mathrm{FeO}(\mathrm{OH})$ & -469.03 & 67] \\
\hline $\mathrm{Mn}^{2+}$ & -227.61 & [67] \\
\hline $\mathrm{Mn}(\mathrm{OH})_{2}$ & -614.63 & 67] \\
\hline $\mathrm{Mn}_{4}^{\mathrm{II}} \mathrm{Mn}_{2}^{\mathrm{III}}(\mathrm{OH})_{12} \mathrm{SO}_{4}$ & {$[-4519,-4436]$} & This work \\
\hline$\gamma-\mathrm{MnO}(\mathrm{OH})_{(\mathrm{s})}$ & -557.2 & [69] \\
\hline$\beta-\mathrm{MnO}(\mathrm{OH})_{(\mathrm{s})}$ & -543.4 & [69] \\
\hline
\end{tabular}

Table 1: Reference Standard Gibbs free energy of formation $\Delta_{\mathrm{f}} \mathrm{G}^{0}\left(\mathrm{~kJ} \cdot \mathrm{mol}^{-1}\right)$. The standard Gibbs energy of formation of groutite $\alpha-\mathrm{MnO}(\mathrm{OH})_{(\mathrm{s})}$ (no data available) was supposed to be close from feitknechtite $\beta-\mathrm{MnO}(\mathrm{OH})_{(\mathrm{s})}$ Indeed, both compounds were reported to be less stable than manganite $\gamma-\mathrm{MnO}(\mathrm{OH})_{(\mathrm{s})}$ [70] with corresponding higher $\Delta_{\mathrm{f}} \mathrm{G}^{0}$ values.

\subsection{Observations during the oxidation}

\subsection{1 pH measurement}

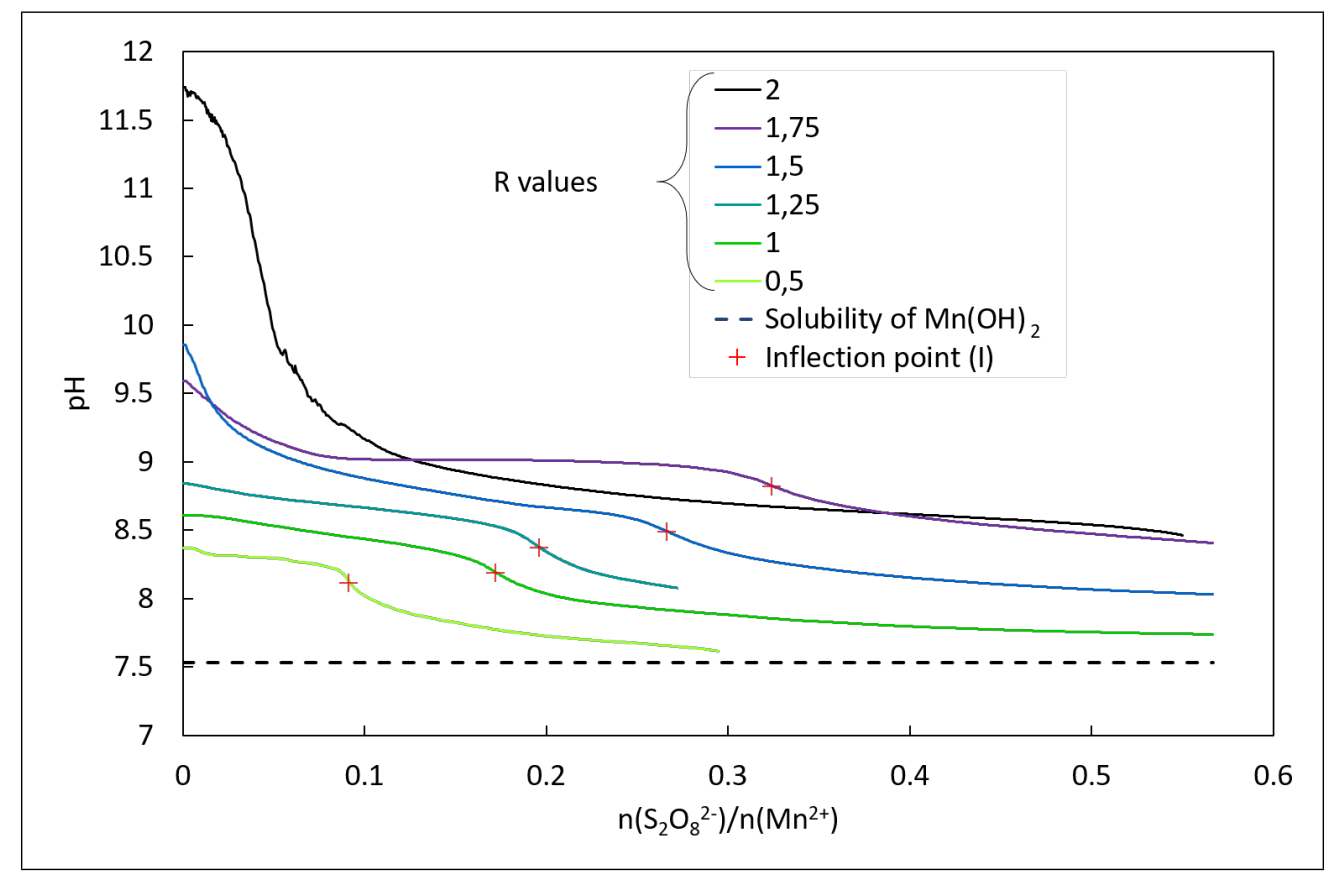

Figure 15: $\mathrm{pH}$ values for the $\mathrm{Mn}^{2+}$ solution after various $\mathrm{NaOH}$ addition characterized by various $\mathrm{R}$ values and during $\mathrm{S}_{2} \mathrm{O}_{8}^{2-}$ addition. Dotted line is the limit of the $\mathrm{Mn}(\mathrm{OH})_{2}$ solubility with a $\mathrm{Mn}^{2+}$ concentration of 0.4 mol. $\mathrm{L}^{-1}$. Red cross are the inflexion points reported on figure 3. 


\subsubsection{Colors of the solids}
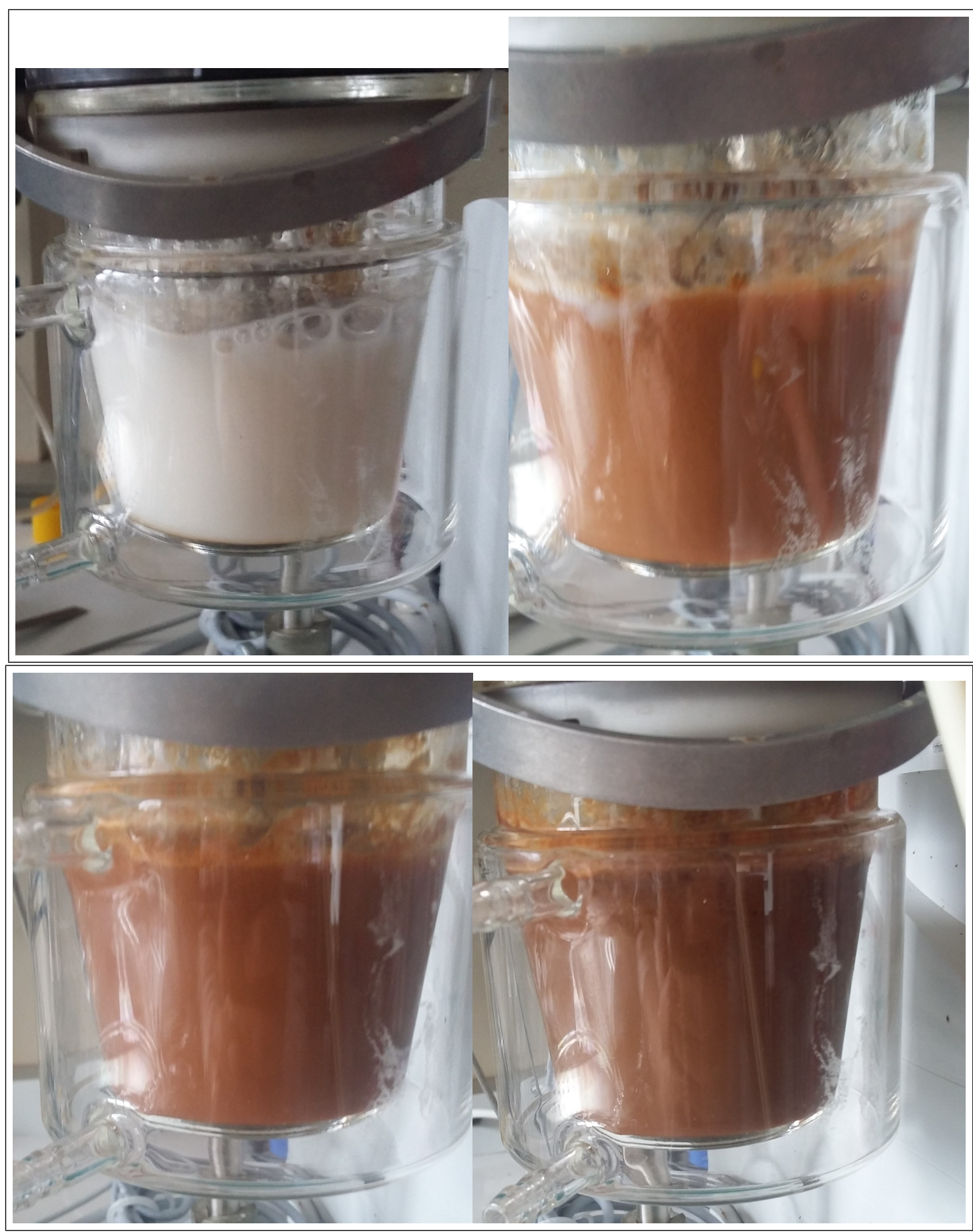

Figure 16: Color of the solution before (up left) and for various addition of $\mathrm{S}_{2} \mathrm{O}_{8}^{2-}$ ( $\mathrm{x}=0.12$ (up right), 0.24 (down left) and 0.30 (down right)) in a $\mathrm{R}=1.5$ solution 